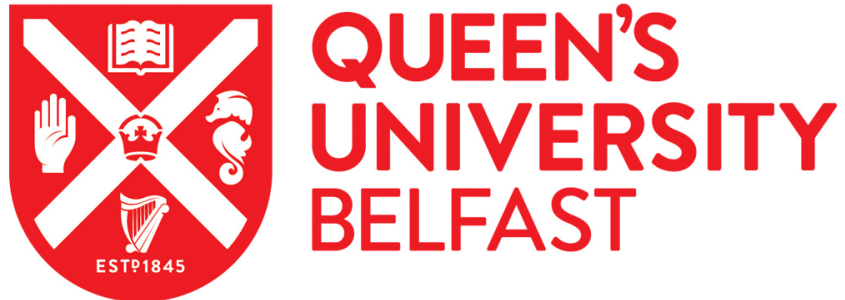

\section{Continuity and Change in Anger and Aggressiveness from Infancy to Childhood: The Protective Effects of Positive Parenting}

Perra, O., Paine, A., \& Hay, D. F. (2020). Continuity and Change in Anger and Aggressiveness from Infancy to Childhood: The Protective Effects of Positive Parenting. Development and Psychopathology, Early Online, xx. https://doi.org/10.1017/S0954579420000243

\section{Published in:}

Development and Psychopathology

\section{Document Version:}

Peer reviewed version

Queen's University Belfast - Research Portal:

Link to publication record in Queen's University Belfast Research Portal

\section{Publisher rights}

(c) 2020 Cambridge University Press.

This work is made available online in accordance with the publisher's policies. Please refer to any applicable terms of use of the publisher.

\section{General rights}

Copyright for the publications made accessible via the Queen's University Belfast Research Portal is retained by the author(s) and / or other copyright owners and it is a condition of accessing these publications that users recognise and abide by the legal requirements associated with these rights.

Take down policy

The Research Portal is Queen's institutional repository that provides access to Queen's research output. Every effort has been made to ensure that content in the Research Portal does not infringe any person's rights, or applicable UK laws. If you discover content in the Research Portal that you believe breaches copyright or violates any law, please contact openaccess@qub.ac.uk. 


\section{Continuity and Change in Anger and Aggressiveness from Infancy to Childhood: The Protective Effects of Positive Parenting}

Early signs of anger and aggression can be identified in infancy. Our aim was to use person-centered methods to identify which infants were most at risk for clinically significant behavioral problems by age 3 and diagnoses of $\mathrm{ODD} / \mathrm{CD}$ by 7 years, while considering the role of family risk factors and positive parenting. A representative British community sample of 304 infants was assessed by multiple informants at mean ages of 6, 21, and 36 months of age. Latent Transition Analysis (LTA) identified three ordered subgroups at each age, with one subgroup (18\%) displaying high levels of physical force as well as anger. These angry aggressive infants were at elevated risk for behavioral problems in early childhood and diagnoses of Conduct Disorder (CD) and/or Oppositional Defiant Disorder (ODD) at 7 years of age. After other risk factors were taken into account, parents' beliefs in warm parenting and their observed positive affect while interacting with their infants were protective factors. These findings indicate the significance of very early manifestations of angry aggressiveness and have relevance for developmental theories of aggression and prevention strategies. 



\section{Continuity and Change in Angry Aggressiveness from Infancy to Childhood: \\ The Protective Effects of Positive Caregiving}

The origins of both anger and aggression can be identified in the first years of life. Anger is a primary emotion that emerges in the months after birth (e.g., Stenberg, Campos, \& Emde, 1983; Lewis, Alessandri, \& Sullivan, 1990; Lorber, DelVecchio, \& Slep, 2015), a few months before infants begin to direct physical force against other people (Eckerman, Whatley, \& Kutz, 1975). Temper tantrums peak in the second and third years (Potegal \& Davidson, 2003), around the time that children with problematic levels of aggression begin to be identified (Côté, Vaillancourt, LeBlanc, Nagin, \& Tremblay, 2006). But is a young child's expression of anger likely to be accompanied by aggression? The aim of our paper was to chart the parallel development of anger and the use of physical force against other people and thereby identify the emergence of a pattern of angry aggressiveness over the first three years of life that might predict Disruptive Impulse Control and Conduct Disorders later in childhood.

The concept of angry aggressiveness extends beyond constructs defined primarily in terms of anger and oppositionality, such as 'difficult temperament' (Bates, 1980) and Oppositional Defiant Disorder, as opposed to aggression, which is defined behaviorally as a symptom of Conduct Disorder (American Psychiatric Association, 2013). Angry aggressiveness is similar to Hattwick's (1936) concept of children's 'contentiousness,' which included both displays of anger and physical aggression. However, anger is more common than aggression. Anger is a primary emotion, expressed in species-specific ways. Some developmental theorists see aggression similarly, as a fundamental human tendency that is universal in the early years of life (e.g., Tremblay, 2010). In contrast, we have hypothesized that, while most infants begin to express anger by the end of the first year, physical 
Positive Parenting and Angry Aggressiveness

aggression is not as common; the literature suggests that it does not occur at high rates and meaningful individual differences are present from the outset (Hay, 2016).

It is important to analyze those individual differences and the risk and protective factors that foster or discourage aggression. The aim of our study was to examine continuity and change in displays of anger and the use of physical force from infancy to childhood, using person-centered (as opposed to variable-centered) statistical methods, which focus on categorizing individuals, not just correlating variables (see below). Person-centered methods allowed us to identify subgroups of infants in a community sample who are already on a pathway toward clinically significant problems with anger management and/or physical aggression, as well as those who show little or no anger or aggression. The person-centered analyses also permitted us to identify those children who might show relatively high levels of anger that was not necessarily combined with physical aggression, in contrast to children who were both angry and aggressive.

We evaluated the contribution of known risk factors for childhood disorder (family adversity and mothers' mental health) and sought evidence for protective factors that might prevent the development of disruptive behavior. In particular, because the experience of parents' warmth helps reduce children's behavioral problems (e.g., Pasalich, Witkiewitz, McMahon, Pinderhughes, \& The Conduct Problems Prevention Research Group, 2016), we tested whether positive parenting would serve as a protective factor, making it less likely that infants would develop clinically significant behavioral problems in childhood. In contrast, we hypothesized that parents' endorsement of physical punishment would convey additional risk to the child.

\section{The Origins of Anger and Aggression in Infancy}

In this study we focus on expressions of anger and physical aggression that are first detected in infancy (e.g., Tremblay, 2004), as opposed to relational aggression, covert 
Positive Parenting and Angry Aggressiveness

conduct problems, and callous-unemotional traits which emerge later in childhood (for a review see Eisner \& Malti, 2015). Anger emerges early as an emotional response to frustrating situations when the infants' goals are blocked or their expectations thwarted (Lewis et al., 1990): from an early age infants express anger through facial expressions, increased motor activity, and negative vocalizations. Despite anger being a primary emotion, individual differences in the proneness to anger are evident in infancy (e.g. Lorber et al., 2015), and a large longitudinal study indicated that atypical patterns of elevated anger at an early age predicted behavior problems in preschool (Brooker et al., 2014).

Physically aggressive behaviors develop during the early years (Tremblay et al., 2004). Individuals differ substantially not just in the absolute levels of physical aggression they show at a given age, but also in their patterns of aggression over time (e.g., Baillargeon et al., 2007; Côte et al., 2006; NICHD Early Child Care Research Network, 2004); a finite number of developmental pathways can describe individual differences in aggressive behavior (Nagin \& Tremblay, 2005; Broidy et al., 2003). Some children may never show aggression; others do so at moderate levels; and some show relatively high levels of aggression that accelerate over time (e.g., Tremblay et al., 2004).

Individual differences in aggression become evident as soon as infants develop the motor abilities necessary to use force against others. For example, approximately $10 \%$ of 12 month-olds within a Dutch community sample displayed oppositional, aggressive, and overactive behavior (van Zeijl et al., 2006). In a Canadian sample, parents' retrospective reports indicated increasing prevalence in the use of physical force against others (e.g., pushing) between 7 and 17 months of age, with fewer than $5 \%$ of infants reported to use force at 7 months, in contrast to $80 \%$ by 17 months (Tremblay et al., 1999). Infants' use of force is correlated with other signs of anger and defiance; for example, in a high risk sample of the children of aggressive parents, infants' anger, physical aggression, defiance, and activity 
Positive Parenting and Angry Aggressiveness

levels consolidated into a single underlying externalizing dimension, which displayed considerable continuity from 8 to 24 months (Lorber et al., 2015).

The available evidence suggests that, at least for some infants, higher levels of anger may cluster in consistent ways with the use of force against others. In this paper we refer to angry aggressiveness to indicate a pattern of behavior where children's manifest expression of anger is accompanied by the use of force against other people, as reported by parents and other individuals who observe the child in different contexts and situations.

Our previous work in a British community sample using variable-centered methods identified individual differences in angry aggressiveness by six months of age (Hay, Perra, et al., 2010). In that study, because anger and aggression are influenced by context (e.g. Anderson \& Bushman 2002; Arsenio \& Lemerise, 2004), we collected information from informants who could draw on experiences with the child in different situations and therefore provide a more reliable assessment of the child's behavior (cf., Alink et al., 2006). Individual differences in angry aggressiveness were stable over time. Informants' reports were validated by direct observation: Informants' ratings of angry aggressiveness were significantly correlated with infants' distress when confined in a car seat and their observed use of physical force against peers (Hay, Perra, et al., 2010). Angry aggressiveness in infancy was correlated with well-known risk factors for conduct disorder (Hay, Mundy, et al., 2011) and predicted aggressive conduct problems in early childhood (Hay et al., 2014) and the children's aggressive choices in a computer game seven years later (Hay et al., 2017).

Studies of the early origins of aggression, conducted in different laboratories and different countries, reveal stable individual differences across the first two years of life. However, the developmental course of aggression shows change as well as continuity. Some children show escalating behavior and develop increasingly severe conduct problems; others eventually desist from the use of force. Although the use of force tends to rise and fall from 
Positive Parenting and Angry Aggressiveness

infancy to early childhood (Alink et al., 2006), that general trend obscures individual trajectories. For example, in one sample, those toddlers who displayed frequent aggressive behavior at 17 months became less aggressive by 29 months (Baillargeon et al., 2007). In another sample, discontinuity in early externalizing behavior was apparent between 8 and 15 months of age (Lorber et al., 2015). The aim of our study was to chart such individual trajectories in angry aggressiveness over time in relation to both risk and protective factors.

\section{Risk and Protective Factors}

Risk and protective factors in the family environment influence whether infants become more or less angry and aggressive over time. Responsive caregivers in stable environments are likely to use consistent socialization strategies that help angry infants reduce their use of aggression. In contrast, toddlers who grow up in a less predictable and unstable environment may learn that aggressive behaviors are an effective way to pursue their aims when there is no guarantee that these may be satisfied in the future.

Family adversity. Some sociodemographic risk factors that promote children's aggressive behavioral problems are active before birth or in the early months of life (e.g., Pawlby et al., 2011; Pickles et al., 2013; van Goozen, Fairchild, Snoek, \& Harold, 2007). In particular, sociodemographic adversity can affect the development of the child during gestation by exposing the fetus to maternal stress, which increases the risk of developing aggression and other behavioral problems (Robinson et al., 2011). Exposure to family adversity may increase risk for behavioral problems indirectly, for example by contributing to economic deprivation that may, in turn, reduce learning opportunities for the child. Sociodemographic adversity may also increase family stress, which in turn may have detrimental effects on family relationships and ultimately on the child's cognitive and socioemotional development (NICHD, 2004). 
Positive Parenting and Angry Aggressiveness

Mothers' mental health. Maternal mental health problems during pregnancy also contribute to children's behavior problems. In particular, stress and depression during pregnancy increases the likelihood of aggression and conduct problems (e.g. Barker, Jaffee, Uher, Maughan, 2011; Hay, Pawlby, et al., 2010; Hay et al., 2014; Mäki et al., 2003). The link between prenatal exposure to mothers' stress and conduct problems is significant even when, due to the use of reproductive technologies, parents are not genetically related to their offspring (Rice et al., 2009).

Parents' attitudes and caregiving practices. It is important to move beyond the foregoing analyses of sociodemographic and psychiatric risk factors to examine the contribution of parents' attitudes and behavior toward their infants. The effect of parents' own antisocial behavior may be partly accounted for by the transmission of genetic risk. However, parents with a history of antisocial behavior may also adopt less effective caregiving practices, which in turn may further increase the risk for their children (e.g., Jaffee, Belsky, Harrington, Caspi, \& Moffitt, 2006).

If infants become increasingly prone to anger and resort to using physical force, the way in which their parents and other caregivers react becomes crucial (Belsky, Woodworth, \& Crnic, 1996; Buck \& Dix, 2014; Shaw, Gilliom, Ingoldsby, \& Nagin, 2003). In accordance with Gottfredson and Hirschi's coercion theory (1990), many studies have shown harsh parental discipline to be a risk factor that promotes children's later aggression (Côté et al., 2006; Shaw et al. 2003, Shaw, Lacourse, \& Nagin, 2005; Tremblay et al. 2004). Parents' harsh and hostile behavior while attempting to discipline their children often generates conflict and thereby strengthens the children's aggressive behavior (Belsky et al., 1996). In fact, parents' use of harsh punishment provides a role model for physical aggression (NICHD, 2004), which their children may later emulate. 
Positive Parenting and Angry Aggressiveness

The study of the role of parental discipline is complicated by societal attitudes and the perceived social desirability of this form of discipline. The use of physical punishment may be difficult to observe when caregivers are aware of being observed; they may be more willing to reveal their attitudes toward the use of harsh discipline when they complete questionnaires designed to control for social desirability effects. Parents' attitudes and beliefs are associated with their caregiving practices (e.g. Socolar and Stein, 1995). Furthermore, caregivers' endorsement of harsh discipline predicts their children's externalizing problems in childhood (e.g. Milner \& Clarke-Stewart, 2008). Therefore, in the present study, we examined the effect of parents' endorsement of physical punishment as a risk factor for their children's angry aggressiveness over time.

In contrast, positive parenting, which includes emotional warmth and responsiveness to children's needs, may lower levels of aggression (NICHD, 2004; Reuben et al., 2016). Positive parenting provides a scaffolding family environment, which helps toddlers manage and regulate their own emotions, thus reducing anger and aggressive behavior (NICHD, 2004). Furthermore, positive caregiving fosters children's own positive social behavior (Boeldt et al., 2012), for example, by modeling effective ways to negotiate and manage conflict (Eisenberg et al., 2009). In one study of children who had displayed problematic behavior, mothers' positive attitudes toward parenting (e.g., their beliefs in praising their children) led to fewer behavioral problems (Denham et al., 2000). In that study, the positive influence of parental attitudes was similar to the effects of their observed behavior. Therefore, parents' broader attitudes as well as their directly observed positive parenting might exert a combined effect on the development of angry aggressiveness.

\section{Gender Differences}

In childhood, boys are more likely than girls to show clinically significant neurodevelopmental problems, including Oppositional Defiant Disorder and Conduct 
Positive Parenting and Angry Aggressiveness

Disorder (Maughan, Rowe, Messer, Goodman, \& Meltzer, 2004). However, these gender differences only gradually emerge over the second and third years of life (Alink et al., 2006; Baillargeon et al., 2007; Hay, Nash, et al., 2011). In the first year, when the capacity for anger and the use of force is first developing, there is little evidence for gender differences. For example, a meta-analysis of the temperament literature showed that boys were not more likely than girls to show negative emotionality, although infant girls did show higher levels of self-regulation (Else-Quest, Shibley Hyde, Goldsmith, \& Van Hulle, 2006). Studies of the early origins of aggression have not found gender differences in the first year of life (Alink et al., 2006; Hay, Nash, et al., 2011; Lorber et al., 2015).

Over the next two years, when toddlers throw tantrums and learn how to kick or use their fists, parents and other caregivers apply gender-differentiated socialization practices (e.g., Fagot \& Hagen, 1984). For example, parents respond to boys' physical aggression in more assertive and directive ways, but, when girls are aggressive, use persuasion and requests to understand the victim's perspective (Smetana, 1989). Gender-differentiated socialization contributes to the increasing divergence between boys and girls. Therefore, when identifying different trajectories toward angry aggressiveness, it is important to test for gender differences.

\section{The Value of Person-Centered Statistical Analyses}

The literature on the early development of aggression has mainly focused on individual differences in the "level" of behavior. Aggressive behavior is often thought of as a single underlying dimension that varies quantitatively across individuals. However, development entails qualitative as well as quantitative change. Infants and toddlers' developing motor and cognitive abilities influence not just the level of their aggressiveness, but also the organization of its emotional and behavioral elements. New behaviors emerge over time. For some infants, an early propensity to express anger may eventually translate 
Positive Parenting and Angry Aggressiveness

into acts of physical force. Other infants who were initially similar in their levels of anger may be much less likely to resort to physical aggression. Therefore, longitudinal analyses of the development of aggression must focus on qualitative changes in anger and the use of force over time, in relation to risk and protective factors.

In this study, we used person-centered analyses to identify subgroups of infants who showed qualitatively different developmental patterns over time. Person-centered statistical methods identify homogenous groups of individuals within a sample, defined by shared characteristics (e.g., von Eye \& Bergmann, 2003). In our study, two types of person-centered analyses — latent class and latent transition analyses — were used to track groups of infants with qualitatively different patterns of angry aggressiveness across the first three years of age, thus identifying those individuals in the sample who were most likely to escalate or deescalate over time. We hypothesized that infants who either showed angry aggressiveness at consistently high levels, or showed a pattern of escalation over time, would be at elevated risk for clinically significant disorder later in childhood.

Such use of person-centered longitudinal methods to identify high-risk subgroups in infancy is relevant for prevention and intervention research, and ultimately for clinical practice. If well-characterized high-risk groups can be identified in the first year of life, effective prevention strategies might begin in infancy, before the high-risk children are already manifesting serious symptoms of disruptive behavior disorders (McMahon \& Frick, 2019). By revealing patterns of individual difference, person-centered methods also address the common assumption that all infants are naturally aggressive.

\section{Specific Aims}

In sum, our specific aims were to: (1) identify subgroups of infants who show different levels and configurations of angry aggressiveness over time; (2) investigate continuity and discontinuity in development by analyzing how subgroup membership might 
Positive Parenting and Angry Aggressiveness change or remain stable from infancy to early childhood; (3) investigate changes in subgroup membership in relation to gender and family risk factors; (4) test for the differential impact of parents' attitudes and behavior that reflect positive parenting as opposed to the endorsement of physical punishment; (5) determine whether those infants with high or escalating levels of angry aggressiveness were at elevated risk for aggressive conduct problems at age 3 years and (6) predict from angry aggressiveness group membership in infancy to clinical diagnoses of Conduct Disorder and/or Oppositional Defiant Disorder with impairment at age 7 years.

We anticipated a degree of discontinuity across development, including patterns consistent with the concept of 'multifinality' (Cicchetti \& Rogosch, 1996), which acknowledges that infants who start out similar might diverge over time. In line with earlier evidence, we hypothesized that boys and girls would display increasingly divergent patterns over time. We hypothesized that positive parenting would be protective whereas parents' endorsement of harsh discipline would increase the risk for children's angry aggressiveness.

\section{Method}

\section{Design}

The Cardiff Child Development Study (CCDS) is a six-wave prospective longitudinal study of the social and emotional development of a nationally representative community sample of firstborn children whose mothers were recruited from antenatal clinics in two Healthcare Trusts in South Wales. Mothers and where possible fathers were interviewed during the last trimester of pregnancy. The children were assessed at mean ages of $6,12,21$, 36 , and 84 months ( 7 years), respectively, in an alternating sequence of home and laboratory visits.

\section{Participants}

Families in which the mother was expecting her firstborn child had been recruited in pregnancy through UK National Health Service (NHS) prenatal services; 332 families 
Positive Parenting and Angry Aggressiveness

participated in pregnancy, with $321(97 \%)$ remaining in the sample after the child was born.

No exclusion criteria were set other than the infant's death, or illness so serious that the infant could not be assessed. The present paper focuses on a subsample of 304 infants (173 boys) for whom there was information on at least one anger or aggression questionnaire item provided by at least one informant, on at least one measurement occasion between infancy and early childhood; this subsample represented $92 \%$ of the original 332 families who had been recruited during pregnancy.

Demographic characteristics of the 304 families included in the subsample for this paper are presented in Table 1. The CCDS sample was found to be nationally representative as shown by analyses that compared family demographic characteristics of the CCDS sample with the subsample of firstborn children in the Millennium Cohort Study, the most recent national birth cohort study in the UK (K. Kiernan, personal communication, April 2009). Procedures were approved by the Cardiff University School of Psychology Research Ethics Committee and the U.K. NHS Multi-Centre Research Ethics Committee.

\section{Insert Table 1}

\section{Procedure}

Pregnancy. During pregnancy, two interviewers visited the participants' homes, administering questionnaires and conducting separate interviews with the mother and, if possible, the other parent (99\% biological fathers; $1 \%$ same-sex partners). Both parents provided information in $80 \%$ of families ( $94 \%$ of couples in committed relationships).

Infancy. $N=301$ families ( $91 \%$ of those recruited in pregnancy) participated in a second home visit with a target age range of 5 to 7 months ( $M 6.64$ months, $S D 0.88$, range 511), with nine other families providing questionnaire data only. Parent-infant interactions were observed across three tasks, each 3 minutes in duration: a free play task in which the parent was asked to play a familiar game; a joint activity task in which the parent was asked 
Positive Parenting and Angry Aggressiveness

to show the infant an activity board with flaps like a book; and a feeding task in which the parent was asked to feed solid food to the infant (or water if the infant was not yet eating solid food). Questionnaires were completed by mothers, fathers and a third family member or friend who knew the infant well.

To enable the comparison of the parents' observed behavior with their attitudes, we focused on the infants' primary caregivers, with $N=295$ (280 mothers and 15 fathers) observed in the interaction tasks (five families have missing data due to technical difficulties with the video and one child could not participate in the tasks due to developmental delay). $N$ $=258$ primary caregivers ( 248 mothers and 10 fathers) completed the parenting questionnaires. Multiple imputation methods were used to deal with missing information on observed and self-reported parenting behavior (see Data Analysis section).

At a mean of 12 months, families were invited to the university to take part in laboratory-based assessments; a brief questionnaire was completed by the family member ( $90 \%$ mothers) who accompanied the infant to the laboratory. Because multiple informants did not report on the infant's behavior at that time, those data are not included in the longitudinal analyses for the present paper.

Toddlerhood. Another home visit with a target age range of 18 to 24 months took place at a mean age of 20.63 months ( $S D 2.26$, range 17 to 30 months). Questionnaires were again completed by mothers, fathers, and a third family member or friend ( $N=258$ families).

Early Childhood. Families were invited to take part in a laboratory visit within a target range of 30 to 42 months. In $N=254$ families, questionnaires were again completed by mothers, fathers, and a third family member or friend at a mean age of 36.12 months (SD 7.18 , range 27 to 66 months).

Middle Childhood. The final assessments in the study were carried out within a target age range of 6 to 7 years during two home visits. $N=287$ children participated at a 
Positive Parenting and Angry Aggressiveness

mean age of 83.28 months (SD 4.54, range 67 to 104 months). Questionnaires were completed by mothers, fathers, and classroom teachers. The primary caregiver ( $97 \%$ mothers) was interviewed about the family environment and the child's mental health, using a semistructured clinical interview.

\section{Measures}

Family adversity. Because many of the indicators of sociodemographic adversity were highly intercorrelated, a general index of child's exposure to maternal factors known to be associated with overall family adversity was created using Principal Component Analysis (PCA). Maternal reports of sociodemographic variables were used for each family, in order to equate the source of information across the different family structures found in this community sample of first-time mothers and infants. These family structures encompassed single mothers and mothers in a relationship with a partner who was not the biological father of the child (including same-sex partners), as well as mothers who were in a committed relationship with the child's biological father. A series of items endorsed by mothers during prenatal interviews and questionnaires contributed to the adversity index:

(a) Occupational status, assessed using the Standard Occupational Classification 2000 (SOC2000; Elias, McKnight, \& Kinshott, 1999), is a recommended method used to measure social class in British cohorts. The highest ranked employment the mother ever had was used to determine her occupational status. If she had never been in paid employment, the highest ranked occupation in her household was used to estimate her social class. Mothers' scores on the SOC2000 scale were dichotomized into the working class and middle/upper class as defined by the SOC2000 criteria;

(b) Maternal education, described by a dichotomous variable indicating whether the mother had failed to attain the basic level of educational qualifications expected in the UK: at least five General Certificate of Secondary Education (GCSE) examinations passed at grades 
A* to $\mathrm{C}$ or, for older members of the sample, the equivalent Certificate of Secondary

Education (CSE) or 'O' level grades;

(c) Mother not being in a committed romantic relationship during the pregnancy, defined as not living with or otherwise having a romantic commitment to the child's biological father;

(d) Mother not being legally married during the pregnancy;

(e) Young maternal age, dichotomized according to whether or not mothers were younger than 20 years of age at the time of the child's birth.

A Principal Components Analysis (PCA) based on the polychoric correlation matrix confirmed that all these categorical items contributed to a single component, with eigenvalues 3.84 and 0.68 for the first and second component extracted, respectively. The first component explained approximately $77 \%$ of the shared variance in these risk indicators. Summary scores derived from the PCA were used in all subsequent analyses as an index for family adversity.

Maternal prenatal depression. The mood disorder and anxiety sections of the Schedules for Clinical Assessment in Neuropsychiatry (SCAN; Wing et al., 1990) were incorporated into the prenatal interviews. Interviewers had received formal training. Independent coding was carried out using DSM-IV criteria, while final decisions concerning clinical diagnosis were made in conferences with two experienced psychiatrists and a trainee clinical psychologist. Significant inter-rater agreement was reached between the clinicians' diagnoses of disorder, $\kappa=.78, p<.001$. A random sample $(20 \%)$ of participants who did not meet caseness criteria was also assessed by two clinicians, confirming that disorder was not present. DSM-IV mood disorder was categorized into Major Depressive Disorder (MDD) or Bipolar Disorder. Mothers were classed as depressed in pregnancy if they had been diagnosed with MDD or Bipolar Disorder with predominantly depressive features in that time period. 
The interview was repeated at the early infant home visit and diagnoses made in the same way, with good reliability, $\kappa=.80, p<.001$.

Mothers' antisocial behavior. During the prenatal interviews, mothers reported on their history of arrest and symptoms of antisocial personality disorder, using the screening questionnaire for the International Personality Disorder Examination (IPDE; Loranger et al., 1994) combined with seven items measuring DSM-IV symptoms of conduct disorder (CD). The resulting composite measure of mothers' past and present antisocial behavior showed good internal consistency (Cronbach's $\alpha=.79$ ) and was further validated by mothers' reports of their history of arrest, $r(323)=.56, p<.001$.

However, preliminary analyses indicated that the inclusion of mothers' antisocial behavior and antenatal depression as covariates caused problems of model convergence. On closer inspection, these problems seemed to be related to the association between these two variables (Spearman $\rho=0.31, p<.001$ ) and problems related to lack of common support (see Murname \& Willett, 2011), i.e., the fact that associations between exposures to risk factors and outcomes cannot be reliably estimated when few participants are present in different regions of the covariates' cross-tabulation (e.g., when only a few mothers who were depressed before birth did not also display antisocial tendencies). To avoid this problem, the measure of mothers' antisocial behavior was dichotomized at the median. Although this resulted in a potential decrease of power to detect associations between outcomes and mothers' antisocial behavior, we reasoned that dichotomizing this variable would result in a more stringent test of the associations, which was preferable than the alternative when considering estimates biased by lack of common support.

Parenting attitudes and behavior. At a mean of 6 months postpartum, the parents' attitudes about childrearing were assessed via the Parental Attitudes toward Childrearing Questionnaire (PACQ; Easterbrooks \& Goldberg, 1984), which includes six items that tap 
Positive Parenting and Angry Aggressiveness into the parents' beliefs in warm parenting (comforting, showing affection, praising, joking and playing, providing attention and feeling satisfaction in being a parent, $\alpha=.69$ ). The composite PACQ warm parenting variable was asymmetric and skewed, and therefore was power-transformed for further analyses. Means, standard deviations, and range of raw scores on this measure are reported in Table 1.

The PACQ also contained two items measuring the parents' endorsement of physical punishment, which were combined (Table 1). This variable was also asymmetric and therefore was log-transformed in further analyses.

During the home observation at the Infancy Visit, the primary caregiver's observed positive affect (smiling and laughing) was coded using 10-second interval time sampling across the three interactive tasks. Independent observers recorded $34 \%$ of the videos with good agreement (median ICC $=.96$ ). A measurement model was constructed that considered the cumulative instances of smiling and laughing displayed by the primary caregiver in the three interaction tasks as indicators. Because the indicators were count variables, the estimator used in the measurement model was MLR in Mplus 7 (Muthén \& Muthén, 2012). The model indicated a good fit, $L R \chi^{2}(972)=683.4, p=1.00$. The Positive Affectscores derived by this measurement model (see Table 1) displayed a distribution approaching normality.

Angry aggressiveness from infancy to early childhood. At the Infancy, Toddlerhood and Early Childhood Visits, up to three informants rated the child's anger and aggressive behavior using the Cardiff Infant Contentiousness Scale (CICS). This instrument, whose name draws on Hattwick's (1936) pioneering work on children's angry aggressiveness, uses age-appropriate items that measure anger and use of physical force, which were embedded into a checklist of normative developmental milestones (e.g., smiles; can sit up by himself/herself; see Hay, Perra, et al, 2010). The infant form of the CICS 
administered at the Infancy Visit contains four age-appropriate items: infants' angry moods, temper tantrums, biting others, and hitting out at others (e.g., moving their arms to strike another person). Two further age-appropriate items were included in the toddler form of the CICS at the Toddler and Early Childhood Visits in order to take into account toddlers' motor development: hitting or kicking to get toys and forcefully grabbing toys or objects from others.

Informants reported on the occurrence of these behaviors in three ordered categories of response (does not occur; sometimes/possibly occurs; often/definitely occurs). The fourand the six-item scales have internal consistency, significant inter-rater agreement, and concurrent and predictive validity (for details see Hay, Perra, et al., 2010; Hay et al., 2014).

CICS data from the Infancy Visit were available for 287 infants; in $61 \%$ of cases, all three informants provided data; in $15 \%$, only one informant provided data. At the Toddler Visit, CICS data were available for 258 children, with all three informants providing information for $67 \%$ and only a single informant in $11 \%$. At the Early Childhood Visit, CICS data were available for 244 children, with information provided by all three informants in $62 \%$ of families and by only one informant in $18 \%$.

The analytic approach used in subsequent analyses requires a focus on individual items from the CICS infant and toddler scales. We obtained a cross-informant composite score for each CICS item by averaging scores across informants at each age and categorizing these scores in three brackets (coded 0,1 , and 2), using as cut points scores of 0.65 and 1.65 to round the average score up to the next category.

CICS questionnaires were available across all three ages for 212 infants (70\%), while $61(20 \%)$ had information on at least two occasions. Analyses of missing data patterns revealed that at each age missingness was significantly and positively associated with higher levels of sociodemographic adversity, but not with prenatal depression or mothers' antisocial 
Positive Parenting and Angry Aggressiveness

behavior. We concluded that missingness was predicted by variables other than the outcome of interest and therefore data were overall missing at random (MAR), i.e., missing in ways that are associated and can be predicted by covariates. Therefore, cases with missing scores on different occasions were still included in subsequent analyses. By adopting Full Information Maximum Likelihood (FIML), latent class models use all available information in the estimation of model parameters. This feature ensures that parameters are estimated more reliably compared to an analysis that only uses complete cases; as long as the reasons for missing data are stochastic (Missing Completely At Random) or dependent on covariates included in the analysis (Missing At Random), the FIML method provides unbiased estimates.

Children's aggressive conduct problems in early childhood. At the Early

Childhood Visit, 254 families reported on the child's clinically significant behavioral and emotional problems using the $1 \frac{1}{2}$ - to 5 -year-old version of the Child Behavior Check List (CBCL; Achenbach \& Rescorla, 1992). The CBCL aggressive problems scale yields an ageappropriate continuous measure of young children's aggressiveness and associated conduct problems. Mothers' ratings on the aggressive problems scale were significantly correlated with fathers' ratings, $r(168)=.46, p<.001$, and with ratings provided by the third informant, $r(172)=.49, p<.001$. A factor score was derived considering all available information provided by up to three informants using a measurement model; mothers', fathers' and third informants' ratings were considered indicators of a latent dimensional construct. These factor scores, analogous to standardized scores, were constrained to have a mean of 0 and $S D=1$. Mplus 7 (Muthén \& Muthén, 2012) was used to implement this measurement model and calculate factor scores. A Maximum Likelihood estimator with robust standard errors (MLR) was used to allow for non-normal distributions of the indicators. 
Positive Parenting and Angry Aggressiveness

Children's mental health at the Middle Childhood Visit. At the Middle Childhood

Visit, the child's primary caregiver was interviewed using the Preschool Age Psychiatric Assessment (PAPA; Egger et al., 2006), which covers the full range of behaviors that are symptoms of psychopathological disorders of children under the age of eight years.

Interviewers were trained by an official PAPA trainer and monitored throughout the data collection period. The data were sent to Duke University for independent analysis, using SAS algorithms designed to identify cases of DSM-IV disorders with clinical impairment. The PAPA has been used to estimate prevalence of CD and ODD in prior studies of epidemiological samples (e.g., Wichstrøm, Berg-Nielsen, Angold, Egger, Solheim, \& Sveen, 2012). In the present sample, $12 \%$ of children met the DSM-IV criteria for CD and/or ODD with significant clinical impairment. Although the PAPA algorithms were based on DSM-IV criteria, we note that the joint focus on CD and ODD is compatible with the approach now taken to identifying these phenomena within the broader category of Disruptive, ImpulseControl and Conduct Disorders in DSM-5.

\section{Data Analysis}

Person-centered analyses were used to investigate individual differences and sequences of change over time in configurations of children's anger and aggressiveness. These methods permit identification of different subgroups of infants who differ in their patterns of anger and use of force. Latent transition analysis (LTA), as opposed to mixture growth models, was used because LTA allowed for the investigation of qualitative changes, particularly changes that might produce newly emerging configurations of angry aggressiveness (Flaherty, 2008). The use of LTA also permitted a focus on patterns of discontinuity across ages (Baillargeon et al., 2007), i.e., identifying children who move from one configuration of angry aggressiveness to a different configuration as they grow older. 
Positive Parenting and Angry Aggressiveness

Data preparation was conducted using Stata 13 (StataCorp, 2013). Latent class and latent transition analyses used Mplus 7 (Muthén \& Muthén, 2012). These analyses were conducted in different stages, following the advice given by Ryoo, Wang, Swearer, Hull, and Shi (2018). The stages of analysis are numbered to map the analytic stages onto the reported findings.

(i) Cross-Sectional Latent Class Analysis (LCA) Models. First, cross-sectional LCA models were tested with increasing number of classes to ascertain the best latent class solution that could describe the different configurations of angry aggressiveness at the Infancy, Toddlerhood and Early Childhood assessments. We assessed the best latent class solutions using the Bayesian Information Criteria (BIC) and the sample-sized adjusted BIC (a-BIC) to compare different models: lower values indicate better fit. Indicators of the quality of classification such as Entropy (McCutcheon, 2002) were also considered, as reported in the supplementary materials.

(ii) Tests for longitudinal measurement invariance. Next, we tested for measurement invariance in the latent class solutions estimated at the different time points, which allowed investigation of the consistency of the latent constructs being assessed, i.e., the different categories of anger and aggressiveness. This step informed the longitudinal measurement model used in subsequent investigations of change across time.

(iii) Latent transition analysis (LTA) with risk factors as covariates. In the next stage of analysis, the longitudinal measurement model identified in (ii) was used to test for changes in angry aggressiveness across age. LTA is an auto-regressive model whereby the current status (e.g. high levels of angry aggressiveness) is determined by the individual's status on a previous measurement occasion. This effectively means that an individual's current status at Time 2 is expressed as a function of the probability of transitioning into that status, given the individual's status at previous Time 1. 
At this stage of analysis, risk factors were introduced as covariates, which allowed us to determine how gender and family risk factors (family adversity, mothers' prenatal depression, and mothers' history of antisocial behavior) were associated with infants' anger and use of force in infancy. Latent categories in toddlerhood and early childhood were then regressed on the same covariates while controlling for the latent status at the previous age. In this way we tested whether these risk factors influenced transitions across age from one latent category to another.

(iv) Latent transition analysis with parents' warmth and endorsement of harsh

punishment as covariates, adjusting for other covariates. At the fourth stage of analysis, we tested whether different transition patterns from Infancy to Toddlerhood, and from Toddlerhood to Early Childhood were associated with positive parenting and/or endorsement of harsh punishment, as measured in infancy. The parents' endorsement of punishment and the positive parenting variables significantly and negatively correlated; in order to avoid collinearity, we introduced these two groups of variables in separate regressions. To this purpose, parents' endorsement of punishment was entered as a covariate in the model described in the third analytic stage (iii). Next, in a further regression, parents' endorsement of warm parenting and observed positive affect during parent-infant interaction were entered into the covariates introduced in stage (iii), thus assessing the adjusted associations between these parenting variables and transition patterns in angry aggressiveness. To allow for missing information in the parenting variables, these analyses were conducted on 50 imputed datasets created using multiple imputation chained equations (Stata 13 command mi: StataCorp, 2013). Auxiliary variables used to increase prediction accuracy included: the angry aggressive latent class affiliation in infancy, toddlerhood, and early childhood; prenatal depression; mother's depression during the infant's first 6 months; the family adversity index; and mother's history of antisocial behavior. The latent transition models in Mplus thus 
Positive Parenting and Angry Aggressiveness averaged parameters across the 50 imputed datasets provided by $N=304$ (i.e. those participants with any information about angry aggressiveness, as described above).

\section{(v) Latent transition analyses to predict aggressive conduct problems in early}

childhood. To investigate whether participants' configurations of anger and aggressiveness from infancy to early childhood predicted aggressive conduct problems at age 3 years, we tested whether infants' anger and aggressiveness status in infancy and toddlerhood predicted their symptoms on the CBCL aggressive scale in early childhood. In order to avoid bias due to missing data in the CBCL scores, missing CBCL scores were imputed in 50 complete datasets using chained equation in Stata 13 (StataCorp, 2013). Auxiliary variables used to increase prediction accuracy included the angry-aggressive category membership in infancy, toddlerhood and early childhood; family adversity; mothers' prenatal depression; and mothers' history of antisocial behavior.

(vi) Latent Transition Analysis in relation to the distal outcomes of CD/ODD with clinical impairment in middle childhood. At the final stage of analysis, we tested whether a child's configuration of angry aggressive behavior in the first years of life predicted whether or not that child met DSM-IV criteria for a diagnosis of CD or ODD in middle childhood. The latter analyses were conducted by running logistic regression models in Stata 13 (StataCorp, 2013); the latent class affiliation estimated in infancy, toddlerhood and early childhood by the latent transition models was considered one of the predictors of the outcome, while controlling for other covariates family adversity index, mothers' history of antisocial behavior, and the child's gender (preliminary checks had shown that prenatal depression was not related to the outcome). In conducting these regressions, we controlled for the uncertainty in assigning children to latent classes by using weights that represented children's probability of being in each one of the latent classes estimated at a given age (the probability weighting methods described in Clarke \& Muthén, 2009). Furthermore, because 
Positive Parenting and Angry Aggressiveness of missing data in the follow-up outcomes of interest, we estimated regression parameters from 50 complete datasets created using Multiple Imputation methods that use chained equations: these are implemented in the $m i$ command of Stata13. Auxiliary variables used to increase prediction accuracy of the outcomes included the angry-aggressive latent class affiliation in infancy, toddlerhood, and early childhood; the family adversity index; and mother's history of antisocial behavior. The results represent averaged parameters across the 50 imputed datasets provided by $N=304$ participants with information about angry aggressiveness.

\section{Results}

\section{Descriptive Statistics}

The average frequency of informants' responses to the angry aggressive items at each age are reported in the supplementary material. Table 1 reports key statistics concerning the risk factors considered. Some of these risk factors were intercorrelated: The family adversity index was significantly related to mothers' antisocial behaviour and prenatal depression, $r(332)=0.40, p<.0001$ and $r(332)=0.44, p<.0001$, respectively, but was not significantly associated with the child's gender, $r(329)=0.10, p=.07$. Mothers' prenatal depression was significantly correlated with the dichotomized measure of mothers' antisocial behavior, $\rho(332)=0.47(p<.0001)$. Although the association between prenatal depression and the gender of the baby was nonsignificant, $\rho(329)=-0.05, p=.65$, the association between mothers' history of antisocial behaviour and having a male child was significant, $\rho(329)=$ $0.20, p=.02$.

The findings regarding parents' positive parenting are drawn from the self-reported and directly observed data provided by the primary caregiver (mother or father) who was present for the interaction tasks. Parents' endorsement of physical punishment was negatively correlated with their beliefs in warm parenting, $r(256)=-0.17, p=.005$. Parents' observed 
Positive Parenting and Angry Aggressiveness

positive affect, as measured by the dimension derived across the three observational tasks, was positively associated with their beliefs in warm parenting, $r(247)=0.14, p=.03$, and was negatively related to their endorsement of physical punishment, $r(245)=-0.13, p=.04$.

\section{Aim 1: Identifying Subgroups of Infants with Different Levels and Configurations of} Anger and Aggressiveness over Time

Data Analysis Step i: Cross-sectional Latent Class Analysis (LCA). In infancy and early childhood, the best solution explaining variability in angry aggressiveness was a 3ordered-class solution. In ordered classes (McCutcheon, 2002), the probability of informants who reported that the infant showed a behavior increased from one class to another. In contrast, in toddlerhood, the best solution was a 4-ordered-class solution, followed by one with three ordered classes. However, closer inspection revealed that the fourth class included fewer than ten participants, who were categorized in the highly angry-aggressive group in the 3-ordered-class solution but manifested even more extreme levels of behavior than other toddlers in that subgroup. This extreme group was not large enough and sufficiently distinct in its features to be considered further; therefore, the 3-ordered-class solution was retained as the final model for all ages.

The three subgroups of children showed qualitative as well as quantitative differences between them. A relatively small group of participants at each age displayed high levels of physical force as well as emotional displays of anger (see Figure 1). We have thus dubbed this group "High anger - High aggression" $(\mathrm{HH})$. A second group displayed elevated levels of anger, but, in contrast to the former one, this group only showed moderate levels of physical force directed at others. This group was dubbed "High anger - Moderate aggression" (HM). Finally, a third group of participants displayed lower levels of angry aggressiveness: this was dubbed the "Low anger - Low aggression" (LL) group. The percentages of infants in the HH, HM, and LL classes at each age are shown in Figure 2. 
Insert Figure 1

Insert Figure 2

\section{Aim 2: To Investigate Continuity and Discontinuity in Angry Aggressiveness by Analyzing How Groups Might Change or Remain Stable from Infancy to Early Childhood}

Data Analysis Step ii: Tests for longitudinal measurement invariance. In LCA, measurement invariance places constraints on the probability of endorsing an item, conditional on latent class membership. We tested different measurement models before imposing autoregressive relations between the latent categorical variables (following recommendations by Nylund, 2007) and used Likelihood-Ratio tests between nested models to test the fit.

A full-invariance model provides a strong assumption of invariance, with each conditional probability of an item constrained to be the same across measurement occasions. However, this highly constrained model did not provide an acceptable fit, as indicated by a worsening of model fit compared to a model with no measurement constraints, $\operatorname{LRT} \chi^{2}(34)=$ $154, p<.001$; therefore, the full-invariance model was rejected.

A partial-invariance model assuming invariance of indicators across the classes was then tested. Based on inspection of conditional probabilities in unconstrained models, the partial-invariance model assumed invariance for all items within the $\mathrm{HH}$ subgroup with the exception of the item angry moods. Furthermore, the frequency of angry moods, hitting out at others, kicking/hitting to obtain toys and grabbing toys was also invariant across age for the HM subgroup. Finally, the frequency of hitting was invariant across ages for the LL subgroup. These constraints are highlighted in Figure 1.

This partial measurement invariance model displayed an acceptable fit compared to the unconstrained non-invariance model, $\operatorname{LRT} \chi^{2}(25)=29.81, p=.23$, as well as lower BIC 
Positive Parenting and Angry Aggressiveness

and a-BIC values respectively, those being 5955.3 and 5739.6 for the non-invariance model vs. 5860.8 and 5724.4 for the partial-invariance model. The HH group was less invariant than the other groups, showing general consistency in its measurement parameters across age. The HM group showed invariance in key indicator behaviors such as anger, hitting and kicking.

The LL class was the most variant class across age, with different behaviors showing different probability from age to age. In sum, with respect to Aim 2, there was some continuity in the categories underlying angry aggressive behavior from infancy to early childhood, insofar as an invariant category of children who displayed high anger and high aggression $(\mathrm{HH})$ and a relatively stable category characterized by high anger but moderate aggression (HM) were consistently identified. The category characterized by lower levels of angry aggressiveness (LL) was somewhat less consistent across age (see Figure 1).

\section{Aim 3: To Investigate the Contribution of the Child's Gender and Family Risk Factors in Predicting Changes in Subgroup Membership over Time}

Associations between variables. Before summarising the results of the Latent Transition Analyses (LTA) with covariates, we first report the associations between the family risk factors and the child's gender and the latent classes identified at each time point (Table 2). There were several significant associations between the latent classes and these predictors. In particular, the maternal risk factors (prenatal depression and history of antisocial behaviour) were associated with children's angry aggressiveness status in infancy, toddlerhood, and early childhood. A strong association was observed between angry aggressiveness status in infancy and family adversity, whereby infants in the HH category displayed higher adversity scores. A nonsignificant trend was observed between gender and angry aggressiveness in infancy, but these variables were significantly associated in early childhood, when boys displayed a higher prevalence of HM angry aggressiveness compared to girls. 


\section{Insert Table 2}

\section{Data Analysis Step iii: Latent Transition Analysis (LTA) with maternal risk}

factors as covariates. The model with partial measurement invariance from infancy to early childhood was taken forward to investigate continuity and transitions from one category to another across age. The child's angry-aggressive status at one age was regressed on his or her angry-aggressive status at the previous age, while controlling for covariates.

In the estimated model, the percentage of $\mathrm{HH}$ infants increased from infancy to toddlerhood and then remained stable from toddlerhood to early childhood. Fewer than half of the infants fell into the HM angry aggressiveness category in infancy, but subsequently the majority of the sample fell into this category. In infancy, nearly half the infants (49\%) had shown little or no anger or use of force, but fewer fell into the LL category in toddlerhood and early childhood.

The transition probabilities of moving from one category to another are reported in Table 3. Despite the general rise in angry aggressiveness from infancy to toddlerhood, some degree of continuity in membership over time was revealed: Over half of all infants remained in the same subgroup as toddlers and $65 \%$ of children remained in the same subgroup from toddlerhood to early childhood. Those infants who were highly angry and aggressive (HH) at 6 months never fell to the LL group in toddlerhood, and only $7 \%$ of the sample showed such an extreme decrease between toddlerhood and early childhood. Transitions from the neither angry nor aggressive group (LL) to the highly angry-aggressive category (HH) were also infrequent. With age, there was an increase from LL to HM levels of angry aggressiveness (see Figure 3). In sum, there was some degree of stability in individual differences across age, against the background of a general increase in anger and use of force between infancy and toddlerhood. 
Positive Parenting and Angry Aggressiveness

The parameters of the multinomial regressions describing the adjusted associations between risk factors and the categories of angry aggressiveness are reported in Table 4 . In what follows we examine these associations in more detail.

\section{Insert Table 4}

Gender differences. Although more boys were in the $\mathrm{HH}$ and $\mathrm{HM}$ categories in infancy (see Table 2), gender differences were not significant when controlling for other covariates, as reported in Table 4. Gender differences became apparent in the patterns of change between toddlerhood and early childhood. Boys were more likely than girls to move from the LL group to the HM group in early childhood $(O R=3.57 ; 95 \%$ CI 1.00 to 12.72$)$.

Family risk factors. Family adversity as measured before the child's birth was strongly associated with the infants' initial levels of anger and their use of force in infancy (see Table 4). After controlling for other covariates, a 1 SD increase in the infant's level of exposure to adversity was associated with a threefold increase in the likelihood of being in the $\mathrm{HH}$ rather than the LL subgroup $(O R=3.12 ; 95 \% C I 1.00$ to 9.76$)$ and with a twofold increase in the odds of being in the HM rather than the LL subgroup $(O R=2.09 ; 95 \% C I$ 1.35 to 3.24$)$.

We then tested for associations between these risk factors and angry aggressiveness at later ages, while controlling for the infant's angry aggressiveness category at the previous age. The multinomial logistic regression parameters revealed a significant association between mothers' antisocial behavior and infants' moderate angry aggressiveness (HM) in toddlerhood: After controlling for other covariates and the infant's level of angry aggressiveness at 6 months, mothers' antisocial behavior was associated with a twofold increase in the odds of moving to the HM rather than the LL group $(O R=2.56 ; 95 \% C I 1.03$ to 6.31$)$. 
Positive Parenting and Angry Aggressiveness

Those infants whose mothers had been depressed during pregnancy displayed increased odds of transitioning into the highly angry-aggressive $(\mathrm{HH})$ class $(3.28,2.76$, and 1.24 in infancy, toddlerhood, and early childhood, respectively), but these associations were not reliable due to the large confidence intervals.

In sum, the family adversity index was significantly associated with initial differences in infants' anger and use of force at the earliest age studied, while the mother's own history of antisocial behavior was associated with escalating patterns in her child's angry aggressiveness between infancy and toddlerhood, with boys in particular showing escalation from toddlerhood to early childhood (see Table 4). No significant associations between prenatal depression and children's patterns of angry aggressiveness were found.

\section{Aim 4: Test for the Differential Impact of Parents' Positive Parenting as Opposed to the Endorsement of Harsh Discipline}

Associations between variables. Table 5 reports the association between latent class affiliation and the parenting variables measured in infancy, as well as the fit of multinomial regressions of latent class affiliation on each of these variables. Parents' beliefs in warm parenting showed a gradient across the three angry-aggressive categories at the Toddler Visit, with the parents of highly angry and aggressive toddlers $(\mathrm{HH})$ less likely to endorse warm parenting and parents of the least angry and aggressive infants (LL) reporting stronger beliefs in warm parenting; these differences approached significance (Table 5). The parents' expressed positive affect during the interaction tasks was unrelated to the infants' initial level of angry aggressiveness at 6 months; however, the parents' positive affect at 6 months significantly predicted the configurations of angry aggressiveness in toddlerhood and early childhood (Table 5). No significant associations between parents' endorsement of physical punishment at six months and their children's level of anger and aggressiveness were observed at any time point. 


\section{Data Analysis Step iv: Latent transition analysis with parents' warmth and endorsement of harsh punishment as covariates, adjusting for other covariates.}

Multiple imputation was used to account for missing parenting variables, with parameters of analyses averaged across 50 complete datasets. The key results are reported in Table 6 .

\section{Insert Table 6}

Parents' endorsement of punishment: In an initial regression, we considered parents' endorsement of punishment as a covariate, while controlling for other covariates. As the preliminary analyses had suggested, the parent's endorsement of punishment was not associated with the child's anger and use of force in infancy or with successive transitions (results reported in supplementary materials).

Parents' observed positive affect and belief in warm parenting: A second regression included the parent's observed positive affect and belief in warm parenting as predictors of the child's angry aggressiveness (Table 6). After controlling for the child's angry aggressiveness status, infants whose parents reported stronger beliefs in warm parenting had decreased odds of moving from the LL class into the HH class between the infancy and toddler assessments $(O R=0.48)$, and significantly reduced odds of moving from the LL class to the HM class $(O R=0.56)$. Thus, the children of parents who held stronger beliefs in warm parenting were less likely to escalate to higher levels of angry aggressiveness over time.

Similarly, those infants who experienced higher levels of parents' positive affect during the interaction tasks at the Infancy Visit were less likely to escalate in their angry aggressiveness between toddlerhood and early childhood; a $1 S D$ increase in parent's observed positive affect in infancy was associated with a $68 \%$ reduction in the odds of moving to the $\mathrm{HH}$ rather than the LL category between toddlerhood and early childhood, $O R$ $=0.32$. Similarly, a $1 S D$ increase in parents' positive affect during the interaction tasks was 
associated with a $66 \%$ decrease in the odds of moving to the HM rather than the LL category between toddlerhood and early childhood, $O R=0.34$ (see Table 6).

In sum, parents' beliefs in warm parenting and observed positive affect while interacting with their infants were associated with de-escalating patterns of angry aggressiveness.

\section{Aim 5: To Test Whether Infants with High or Escalating Levels of Angry Aggressiveness Were at Elevated Risk for Aggressive Conduct Problems at Age 3 Years Data Analysis Step v: Latent transition analyses to predict aggressive conduct} problems in early childhood. An unconditional latent transition model was used to assess associations between angry aggressiveness categories in infancy and toddlerhood and the CBCL aggression scale factor scores in early childhood ( $M=36$ months). Overall, 254 infants who were included in the latent transitions analyses had been assessed by one or more informants (mother, father, or other family member) using the CBCL aggression scale.

Figure 3 displays the means and 95\% CI of the CBCL Aggression Scale by latent class affiliation in infancy, toddlerhood and early childhood. Separate multiple regressions examined the latent class affiliation at mean ages of 6 and 21 months as predictors of the CBCL aggression scores. Parameter estimates were weighted by individuals' probability of being in a given angry-aggressiveness subgroup at each age respectively, thus controlling for uncertainty in estimated latent class affiliation (Clark \& Muthén, 2009). The regression models also controlled for risk factors (child's gender, family adversity, mothers' prenatal depression and mothers' history of antisocial behavior). Analyses were conducted averaging parameters across 50 complete datasets created using chained equations.

\section{Insert Figure 3}

Prediction from infancy. The findings revealed a significant association between angry-aggressive status in infancy and CBCL aggression scale scores in early childhood, $F$ 
Positive Parenting and Angry Aggressiveness

$(6,288.4)=3.61, p<.01$. After controlling for other covariates, those infants in the HM category, as contrasted with infants in the $\mathrm{HH}$ category, had significantly lower CBCL aggression scale scores (coefficient $=-0.45, S E=.21, t=-2.16, p=.032$ ), as did those infants who had shown the lowest levels of angry aggressiveness at 6 months (coefficient $=-0.70, S E$ $=.21, t=-3.25, p<.001)$.

Prediction from toddlerhood. Latent class status in toddlerhood also significantly predicted CBCL aggression scores in early childhood, $F(6,287.5)=6.93, p<001$. Compared to the HH group in toddlerhood, those in the HM group had lower CBCL aggression scores (coefficient $=-0.56, S E=.13, t=-4.36, p<.001$ ), as did those who had shown little or no anger or aggression in toddlerhood (coefficient $=-0.85, S E=.15, t=-5.72$, $p<.001)$

In sum, the findings demonstrated predictive associations, whereby infants showing the highest levels of anger and use of force in infancy were reported to have the greatest number of aggressive conduct problems by 3 years of age (Figure 4).

\section{Aim 6: To Test Whether Infants with High and/or Escalating Levels of Angry Aggressiveness Were at Elevated Risk for Clinical diagnoses of Conduct Disorder and/or Oppositional Defiant Disorder in Middle Childhood}

Data Analysis Step vi: Latent transition analyses to predict the distal outcome of CD/ODD with clinical impairment in middle childhood. When the PAPA interview was administered at a mean age of 7 years, $33(12 \%)$ of the children met criteria for CD or ODD with clinically significant impairment. Two-way crosstabulations revealed associations between the angry aggressiveness subgroups in infancy and toddlerhood and diagnoses of $\mathrm{CD} / \mathrm{ODD}$ in childhood. Notably, about a quarter (25\%) of those in the HH group in infancy, toddlerhood and middle childhood met diagnostic criteria for CD/ODD with clinical impairment at 7 years of age (Table 7). 


\section{Insert Table 7}

Associations between angry-aggressive categories in the first three years and diagnoses of $\mathrm{CD} / \mathrm{ODD}$ at age 7 persisted after controlling for covariates (gender, family adversity, mothers' history of antisocial behavior) in logistic regression models. Analyses were conducted on an imputed complete dataset to avoid bias due to incomplete data.

Prediction from infancy to diagnosis. A marginal association was observed between angry-aggressive categories in infancy and CD/ODD at 7 years (Figure 4). Compared to infants in the LL group in infancy, those in the HM subgroup displayed a two-fold increase in the odds of meeting diagnostic criteria for $\mathrm{CD} / \mathrm{ODD}$ at 7 years $(O R=2.42,95 \% \mathrm{CI} 0.95$ to $6.13, t=1.86, p=.06)$.

Prediction from toddlerhood to diagnosis. A significant association was observed between angry-aggressive categories in toddlerhood and CD/ODD at 7 years. Compared to those in the LL category, toddlers in the HH group displayed over a fourfold increase in the odds of meeting diagnostic criteria for $\mathrm{CD} / \mathrm{ODD}$ at 7 years of age $(O R=4.75,95 \% C I=1.16$ to $19.51, t=2.16, p=.03)$.

Prediction from early childhood to diagnosis. A marginal association was also observed between being in the HH group in early childhood and CD/ODD at 7 years. Compared to those in the LL category, those toddlers categorized as highly angry aggressive displayed a nearly eightfold increase in the odds of meeting criteria for CD/ODD $(O R=7.94$, $95 \% C I=0.91$ to $69.48, t=1.87, p=.06)$. In sum, the results indicated a pattern of associations between early levels of anger and aggressiveness and risk for CD/ODD at 7 years (see Table 6 and Figure 4). 


\section{Discussion}

The findings of these person-centered analyses of a representative longitudinal sample confirm earlier evidence for significant individual differences in anger and the use of force in infancy (Côte et al., 2006; NICHD Early Child Care Research Network, 2004; Lorber et al., 2015), and have corroborated and extended the prior variable-centered analyses on our sample (Hay, Perra, et al., 2010; Hay et al., 2014). In terms of the theoretical debates about the developmental origins of aggression, the new evidence from person-centered analyses provides further support for our hypothesis that individual differences in the display of anger and the use of physical force are already present in the first year of life (Hay, 2016). Our findings provide information on the clustering across early stages of development of anger and the use of force against other people, lending support to our conceptualization of angry aggressiveness as children's proneness to displays of anger combined with physical aggression.

Our findings extend existing evidence by (1) identifying particular subgroups of infants at different levels of risk for problematic aggression; (2) demonstrating patterns of change and discontinuity over time that showed either escalation or de-escalation from earlier levels of angry aggressiveness; (3) providing evidence for both risk and protective factors that influence the pattern of change over time and risk for later conduct problems; and (4) providing evidence that very high levels of angry aggressiveness in infancy and toddlerhood are relatively uncommon and may herald the development of clinically significant oppositionality and conduct problems later in childhood.

\section{Identification of Subgroups of Infants at Differential Risk}

We used latent class and latent transition analysis to chart changes in angry aggressiveness from early infancy to age three years. These methods permitted detection of emerging behavior patterns, beyond merely quantitative changes in the frequency of 
Positive Parenting and Angry Aggressiveness

particular behaviors across development (Baillargeon et al., 2007; Connell et al., 2008). The identification of three ordered groups by LTA may initially suggest an underlying dimensionality of angry aggressive behavior. However, closer inspection of these categories revealed important qualitative as well as quantitative differences that influenced the pattern of change in angry aggressiveness over the first three years. Crucially, these categories indicated differences in the range of behaviors shown: To emphasize these qualitative differences, we have dubbed the groups that showed higher levels of angry aggressiveness High anger - High Aggression ( $\mathrm{HH})$, and High anger - Moderate aggression (HM). While infants and toddlers in the $\mathrm{HH}$ and $\mathrm{HM}$ angry aggressiveness category were both prone to angry outbursts, they diverged in their use of physical force (Figure 1). Compared to the HH subgroup, individuals in the HM subgroup seemed better able to avoid translating their anger into physical aggression.

Not all infants were angry or aggressive. At all ages, some children showed very low levels of both anger and aggression: this group was dubbed Low anger - Low aggression (LL). However, over time, most children in the sample were reported to show higher levels of anger, with the size of the HM subgroup increasing from infancy to toddlerhood. Thus, across the toddler years, displays of anger become more normative but physical force continued to be used more sparingly in both the HM and the LL group. It is noteworthy that the most common form of physical force for the HM group was a form of instrumental aggression, grabbing on toys; in contrast, the HH group were more likely to direct force against other people's bodies.

Again, it is important to note that these subgroups could reliably be identified by six months of age. Previous investigators have suggested that in infancy there would be individual differences in proneness to anger, but only at a later stage would that anger be expressed through physical aggression (Alink et al., 2007; Tremblay, 2003). The results of 
Positive Parenting and Angry Aggressiveness

our study do not support this claim. Rather, even at six months of age, a minority of infants in the HH group were not only expressing anger but were also reported to hit out at or bite others; the informants' reports were validated by observations of those infants' directly observed use of force against peers (Hay, Mundy, et al., 2011). The divergence of our findings from received wisdom in the literature is not due to sample discrepancies: The rates of highly angry aggressive toddlers in our community sample resemble the rates of highly aggressive children identified in larger surveys of aggression (e.g., Tremblay et al., 2004).

\section{Consistency and Change in Subgroup Membership over Time}

Overall, although many children remained in the same category across measurement points, some change did occur, which corroborates earlier findings (Baillargeon et al., 2007; Lorber et al., 2014). The proportion of infants classified as high in angry aggressiveness (HH) increased over time, an increase that was primarily accounted for by infants in the high anger - moderate aggression (HM) group who moved into the HH category by the time of the Toddler Visit. This shift in subgroup membership over time may partly reflect the wellestablished increases in temper tantrums (Potegal \& Davidson, 2003), possibly because children's developing locomotor skills increase opportunities for frustration and conflict with family members (Campos, Kermoian, \& Zumbahlen, 1992). Some changes in angry aggressive behavior occur during the transition from infancy to toddlerhood (e.g., Lorber et al., 2014).

Nevertheless, despite normative increases in the occurrence of tantrums and development of the motor abilities needed to deploy force against other people, those infants in the LL group who showed the lowest levels of angry aggressiveness did not move into the $\mathrm{HH}$ group at later ages. Some change occurred in the opposite direction, with some $\mathrm{HH}$ infants moving down to the HM category; however, those infants in the HH group never 
moved all the way down to the LL group. Rather, HH infants remained at elevated risk for aggressive conduct problems at 36 months.

\section{Gender Differences}

Patterns of change were associated with gender differences; compared to girls, boys were more likely to show escalation from LL to HM angry aggressiveness. However, these gender differences did not emerge until early childhood. This finding corroborates other studies indicating that, while individual differences in anger and use of force are already present in infancy, gender differences emerge gradually over the first three years of life (Alink et al., 2006; Baillargeon et al., 2007; Hay, Nash, et al., 2011; Hay et al., 2014). This emerging divergence between girls and boys probably derives from a series of cascading factors (Hay, 2016). Some of these are biological, for example gender differences in maturation rate and males' higher susceptibility to neurodevelopmental problems (Hay, 2007). Others are related to cultural norms and differences in socialization processes, for example gender-differentiated treatment by parents (e.g. Smetana, 1989).

Some investigators have argued that the biological differences between girls and boys may moderate the relationships between early risk factors and children's problem behavior (e.g. NICHD Early Child Care Research Network, 2004). This issue is further complicated by temperament (e.g. van Zeijl et al., 2007) and emerging differences in self-regulation that drive girls' and boys' differential susceptibility to parenting practices (Chang, Olson, Sameroff, \& Sexton, 2011). For example, in future work, it would be important to explore gender differences in response to positive parenting, which we have here shown to be a protective factor against the escalation of angry aggressiveness.

Although none of these factors alone explain the eventual gender difference, together they produce a cascade of developmental outcomes that lead to the striking differences in later childhood. Emerging gender differences may also be further amplified by young 
Positive Parenting and Angry Aggressiveness

children's preference for same-sex interaction; peers as well as parents may foster gender differences in angry aggressiveness (Hay, 2007; Hay, Nash, et al., 2011).

\section{The Influence of Family Risk Factors}

Sociodemographic adversity was associated with increased odds of a child being in the $\mathrm{HH}$ angry aggressiveness group by six months of age, replicating findings from other studies (NICHD Early Child Care Research Network, 2004; Lorber et al., 2014; Shaw et al., 2005; Tremblay et al., 2004; van Zejl et al., 2006). Exposure to adverse family circumstances may contribute to increased risk for problematic behavior in different ways. Some mechanisms may be more direct: Adversity (e.g. economic hardship, low educational attainment, and lack of social support) may raise pregnant women's levels of stress, which in turn may interfere with the development of infants' stress response systems (van Goozen et al., 2007). Adversity may increase stress for the whole family, thus contributing to social environments and caregiving practices that amplify propensities for dysregulated and disruptive behavior (NICHD Early Child Care Research Network, 2004). Our findings suggest that exposure to social adversity predicted inter-individual differences that were already evident at a very early age.

In our sample, other risk factors were associated with escalation of angry aggressiveness from infancy to toddlerhood. In particular, the mothers' own history of antisocial behavior predicted infants' escalation from LL to HM levels of angry aggressiveness. Genetic influence and gene-environment interplay may contribute to the observed link between parents' antisocial behavior and escalation of angry aggressiveness. It would be useful to test for such influences in genetically informative designs.

\section{Positive Parenting as a Protective Factor against the Escalation of Aggression}

Our findings also draw attention to the importance of parents' beliefs in positive parenting and their expression of enjoyment while interacting with their infants, which 
Positive Parenting and Angry Aggressiveness complements earlier findings of a link between difficulties in the mother-infant relationship and infants' early anger and aggressiveness (Lorber et al., 2015). Positive parenting protected against the escalation of angry aggressiveness from infancy to childhood; parents' beliefs in warm parenting promoted de-escalating patterns of angry aggressiveness from infancy to early childhood. The parents' observed smiling and laughing while interacting with their infants similarly predicted de-escalation of angry aggressiveness.

Previous studies have suggested that parents' influence on the development of aggression may be particularly important in toddlerhood, a time when parents' responses to toddlers' frustration and aggression may play a crucial role (Belsky et al., 1996; Shaw et al., 2003). However, our results draw attention to the importance of earlier parent-infant interaction and parents' attitudes and values that are already established in infancy. Positive interaction between infants and caregivers promotes emotion regulation, which may in turn help infants deal with emotional challenges without showing extreme anger or resorting to physical force (NICHD Early Child Care Research Network, 2004). Parental warmth also supports toddlers' on-task planning behavior and reduces impulsivity (Reuben et al., 2016). Parents' beliefs in warm parenting may promote positive and supportive interactions between parent and child, even when the child's behavior becomes increasingly more challenging in the toddler years. In future work it would be important to acknowledge the bidirectionality of parent-child relationships and examine children's effects on their parents' attitudes and expression of emotion, and how that might influence parents' warmth and parenting strategies over time.

Our findings showed that positive parenting was protective against the escalation of angry aggressiveness across all three subgroups, which has important implications for early prevention strategies. Even those infants who are already showing high levels of angry aggressiveness profit from a warm caregiving environment and positive parental attitudes. 


\section{Long-term Consequences of Early Angry Aggressiveness}

Individual differences in angry aggressiveness in infancy and toddlerhood were predictive of aggressive conduct problems by three years of age and clinically significant Disruptive, Impulse Control and Conduct Disorders by 7 years of age. These findings support our claim that, even in early stages of development, angry aggressiveness represents a coherent behavioral construct, and individual differences in infants' and toddlers' expression of angry aggressiveness hold significance for their future development and adaptation to the social world.

Some explanations of the developmental trends we have observed may invoke cumulative effects of risk factors. For example, adverse family circumstances contribute to more unstable family relationships over the course of childhood, which in turn has detrimental effects on the child's emotional and behavior development. It is also possible that early-appearing individual differences in angry aggressiveness may contribute to the development of clinically significant problems through a process of 'reverse causality': Infants' and toddlers' early forms of aggressive behavior may evoke more negative parenting practices (e.g., harsh discipline), in an attempt to control the child's behavior. However, our results showed that early-appearing signs of angry aggressiveness led to less adaptive and problematic behavior later in childhood, regardless of the parents' inclinations to use harsh punishment. In contrast, positive parenting was protective.

\section{Limitations of the Study}

The analyses presented in this paper rely heavily on informants' reports of infants' angry aggressiveness and behavioral problems, and thus some continuity over time may reflect shared methods variance. We tried to address this problem by using multiple informants who observed the infant's behavior in different contexts (see also Alink et al., 2006). There was a higher probability of receiving reports from only one informant when 
Positive Parenting and Angry Aggressiveness

families lived under challenging conditions. However, most infants in the sample were reported on by at least two informants and the informants' reports showed good inter-rater agreement. Furthermore, the ratings of angry aggressiveness across informants were validated at each age by objectively observed measures of infants' frustration and aggressive interactions with peers (Hay, Perra, et al., 2010; Hay et al., 2014).

Although the sample size might also be seen as a limitation, compared to studies of larger populations, recruitment of a sample of moderate size permitted the use of direct observation in naturalistic settings as well as multiple informants. There were relatively low levels of attrition and the longitudinal analyses reported here used robust statistical procedures, including the use of multiple imputation methods to counter bias due to nonresponse. The categorization of infants into subgroups was not derived through arbitrary cutoff points but rather through statistical probability models.

\section{Implications of the Findings}

Our longitudinal study allowed us to take an explicitly developmental perspective, using person-centered methods to move beyond earlier variable-centered evidence for continuity of individual differences at the group level to a focus on individual patterns of escalation and de-escalation over time. The person-centered approach provided additional insight into the way in which positive parenting can inhibit the escalation of aggression.

Our findings indicate that, as much as we might like to assume that most toddlers are aggressive and naturally grow out of it, there is considerable benefit in acknowledging that a minority of one- and two-year-olds who show very high levels of anger and use of force against other people are already on a pathway toward clinically significant conduct problems. Appreciation of individual variation in early infancy and its consequences for later problems may lead to screening procedures that help identify those infants and parents who are in particular need of support. The encouraging finding that positive parenting can help prevent 
Positive Parenting and Angry Aggressiveness

the escalation of angry aggressiveness from infancy to early childhood provides important evidence that can inform the development of very early prevention strategies to lower a child's risk for serious conduct problems. We have shown that prevention strategies that encourage positive parenting could begin before the first birthday. 


\section{References}

Achenbach, T.M., \& Rescorla, L.A. (1992). Manual for the ASEBA Preschool Forms and Profiles. Burlington, VT: University of Vermont, Department of Psychiatry.

Alink, L. R. A., Mesman, J., van Zeij1, J., Stolk, M. N., Juffer, F., Koot, H. M., BakermansKranenburg, M.J., \& van IJzendoorn, M. H. (2006). The early childhood aggression curve: Development of physical aggression in 10-to 50-month-old children. Child Development, 77, 954-966. doi:10.1111/j.1467-8624.2006.00912.x

American Psychiatric Association. (2013). Diagnostic and statistical manual of mental disorders (5 $5^{\text {th }}$ ed.). DSM-5. Washington, DC: American Psychiatric Publishing.

Anderson, C., \& Bushman, B. (2002). Human aggression. Annual Review of Psychology, 53, 27-51. doi:10.1146/annurev.psych.53.100901.135231

Arsenio, W., \& Lemerise, E. (2004). Aggression and moral development: Integrating social information processing and moral domain models. Child Development, 75, 987-1002. doi:10.1111/j.1467-8624.2004.00720.x

Baillargeon, R. H., Zoccolillo, M., Keenan, K., Côté, S., Pérusse, D., Wu, H-X., Boivin, M., \& Tremblay, R. E. (2007). Gender differences in physical aggression: A prospective population-based survey of children before and after 2 years of age. Developmental Psychology, 43(1), 13-26. doi: 10.1037/0012-1649.43.1.13

Barker, E. D., Jaffee, S. R., Uher, R., \& Maughan, B. (2011). The contribution of prenatal and postnatal maternal anxiety and depression to child maladjustment. Depression and Anxiety, 28(8), 696-702. doi:10.1002/da.20856

Bates, J. (1980). The concept of difficult temperament. Merrill-Palmer Quarterly, 26, 299319. 
Positive Parenting and Angry Aggressiveness

Belsky, J., Woodworth, S., \& Crnic, K. (1996). Trouble in the second year: Three questions about family interaction. Child Development, 67(2), 556-578. doi:10.1111/j.14678624.1996.tb01751.x

Boeldt, D. L., Rhee, S. H., DiLalla, L. F., Mullineaux, P. Y., Schulz-Heik, R. J., Corley, R. P., Young, S.E., \& Hewitt, J. K. (2012). The association between positive parenting and externalizing behavior. Infant and Child Development, 21(1), 85-106. doi:10.1002/icd.764

Broidy, L., Nagin, D.S., Tremblay, R. E., Bates, J., Brame, B., Dodge, K. A., Fergusson, D., Horwood, J. L., Loeber, R., Laird, R., Lynam, D. R., Moffitt, T. E., \& Pettit, G. S. (2003). Developmental trajectories of childhood disruptive behaviors and adolescent delinquency: A six-site, cross-national study. Developmental Psychology, 39(2), 222245. doi 10.1037/0012-1649.39.2.222

Brooker, R. J., Buss, K. A., Lemery-Chalfant, K., Aksan, N., Davidson, R. J., \& Goldsmith, H. H. (2014). Profiles of observed infant anger predict preschool behavior problems: Moderation by life stress. Developmental Psychology, 50, 2342-2352. doi: $10.1037 / \mathrm{a} 0037693$

Buck, K. A., \& Dix, T. (2014). Parenting and naturally occurring declines in the antisocial behavior of children and adolescents: A process model. Journal of Family Theory \& Review, 6(3), 257-277. doi:10.1111/jftr.12042

Campos, J. J., Kermoian, R., \& Zumbahlen, M. R. (1992). Socioemotional transformations in the family system following infant crawling onset. New Directions for Child and Adolescent Development, 55, 25-40. doi: 10.1002/cd.23219925504

Campos, J. J., Kermoian, R., \& Zumbahlen, M. R. (1992). Socioemotional transformations in the family system following infant crawling onset. In N. Eisenberg \& R. A. Fabes 
Positive Parenting and Angry Aggressiveness (Eds.), New directions for child development, No, 55: The Jossey-Bass education series. Emotion and its regulation in early development (pp. 25-40). Jossey-Bass.

Chang, H., Olson, S. L., Sameroff, A. J., \& Sexton, H. R. (2011). Child effortful control as a mediator of parenting practices on externalizing behavior: Evidence for a sexdifferentiated pathway across the transition from preschool to school. Journal of Abnormal Child Psychology, 39, 71-81. doi:10.1007/s10802-010-9437-7

Cicchetti, D., \& Rogosch, F.A. (1996). Equifinality and multifinality in developmental psychopathology. Development and Psychopathology, 8, 597-600. doi.org/10.1017/S0954579400007318

Clarke, S. L., \& Muthén, B. (2009). Relating latent class analysis results to variables not included in the analysis. Retrieved from http://statmodel2.com/download/relatinglca.pdf

Connell, A., Bullock, B. M., Dishion, T. J., Shaw, D., Wilson, M., \& Gardner, F. (2008). Family intervention effects on co-occurring early childhood behavioral and emotional problems: A latent transition analysis approach. Journal of Abnormal Child Psychology, 36(8), 1211-1225. doi: 10.1007/s10802-008-9244-6

Côté, S., Vaillancourt, T., LeBlanc, J. C., Nagin, D. S., \& Tremblay, R. E. (2006). The development of physical aggression from toddlerhood to pre-adolescence: A nationwide longitudinal study of Canadian children. Journal of Abnormal Child Psychology, 34(1), 71-85. doi: 10.1007/s10802-005-9001-z

Easterbrooks, M., \& Goldberg, W. (1984). Toddler development in the family: Impact of father involvement and parenting characteristics. Child Development, 55(3), 740-752. doi: $10.2307 / 1130126$ 
Eckerman, C. O., Whatley, J. L., \& Kutz, S. L. (1975). Growth of social play with peers during the second year of life. Developmental Psychology, 11(1), 42-49. doi: $10.1037 / \mathrm{h} 0076131$

Eisenberg, N., Valiente, C., Spinrad, T. L., Cumberland, A., Liew, J., Reiser, M., Zhou, Q., Losoya, S. H. (2009). Longitudinal relations of children's effortful control, impulsivity, and negative emotionality to their externalizing, internalizing, and co-occurring behavior problems. Developmental Psychology, 45, 988-1008. doi:10.1037/a0016213

Eisner, M.P., \& Malti, T. (2015). Aggressive and violent behavior. In R. Lerner (Ed.), Handbook of Child Psychology and Developmental Science. Vol. 3. (M. Lamb, Vol. Ed.) Socioemotional processes. Chichester: Wiley. https://doi.org/10.1002/9781118963418.childpsy319

Elias, P., McKnight, A., \& Kinshott, G. (1999). SOC 2000: Redefining skill: Revision of the Standard Occupational Classification. Skills Task Force Research Paper 19. Retrieved from http://dera.ioe.ac.uk/15135/

Else-Quest, N. M., Shibley Hyde, J., Goldsmith, H. H., \& Van Hulle, A. (2006). Gender differences in temperament: A meta-analysis. Psychological Bulletin, 132, 33-72. doi:10.1037/0033-2909.132.1.33

Denham, S. A., Workman, E., Cole, P. M., Weissbrod, C., Kendziora, K. T., \& Zahn-Waxler, C. (2000). Prediction of externalizing behavior problems from early to middle childhood: The role of parental socialization and emotion expression. Development and Psychopathology, 12, 23-45. doi:10.1017/S0954579400001024

Fagot, B. I., \& Hagan, R. (1985). Aggression in toddlers: Responses to the assertive acts of boys and girls. Sex Roles: A Journal of Research, 12, 341-351. doi:10.1007/BF00287600 
Positive Parenting and Angry Aggressiveness

Flaherty, B. P. (2008). Testing the degree of cross-sectional and longitudinal dependence between two discrete dynamic processes. Developmental Psychology, 44(2), 468-480. doi:10.1037/0012-1649.44.2.468

Gottfredson, M. R., \& Hirschi, T. (1990). A general theory of crime. Stanford, Calif.: Stanford University Press.

Hattwick, B.W. (1936). Interrelations between the preschool child's behavior and certain factors in the home. Child Development, 7, 200-226. doi:10.2307/1125370

Hay, D. F. (2007). The gradual emergence of sex differences in aggression: alternative hypotheses. Psychological Medicine, 37, 1527-1537. doi:10.1017/S0033291707000165

Hay, D.F. (2016). The early development of human aggression. Child Development Perspectives, 11, 102-106. doi:10.1111/cdep.12220

Hay, D. F., Johansen, M. K., Daly, P., Hashmi, S., Robinson, C., Collishaw, S., \& van Goozen, S. (2017). Seven-year-olds' aggressive choices in a computer game can be predicted in infancy. Developmental Science, 21, e12576. doi:10.1111/desc.12576

Hay, D. F., Mundy, L., Carta, R., Roberts, S., Carta, R., Waters, C. S., Perra, O. Jones, R., Jones, I., Goodyer, I., Harold, G., Thapar, A., \& van Goozen, S. (2011). Known risk factors for violence predict 12-month-old infants' aggressiveness with peers. Psychological Science, 22, 1205-1211. doi: 10.1177/0956797611419303

Hay, D.F., Nash, A., Caplan, M., Swartzentruber, J., Ishikawa, F., \& Vespo, J.E. (2011). The emergence of gender differences in physical aggression in the context of conflict between young peers. British Journal of Developmental Psychology, 29, 158-175. doi: 10.1111/j.2044-835X.2011.02028.x

Hay, D. F., Pawlby, S., Waters, C. S., Perra, O., \& Sharp, D. (2010). Mothers' antenatal depression and their children's antisocial outcomes. Child Development, 81, 149-165. doi: $10.1111 / \mathrm{j} .1467-8624.2009 .01386 . x$ 
Positive Parenting and Angry Aggressiveness

Hay, D. F., Perra, O., Hudson, K., Waters, C. S., Mundy, L., Goodyer, I., Harold, G. T., Thapar, A., \& van Goozen, S. (2010). Identifying precursors to aggression: Psychometric properties of the Cardiff Infant Contentiousness Scale (CICS). Aggressive Behavior, 36, 351-357. doi:10.1002/ab.20363

Hay, D. F., Waters, C. S., Perra, O., Swift, N., Kairis, V., Phillips, R., Jones, R., Goodyer, I., Harold, G., Thapar, A., \& van Goozen, S. (2014). Precursors to aggression are evident by six months of age. Developmental Science, 17, 471-480. doi: 10.1111/desc.12133

Jaffee, S., Belsky, J., Harrington, H.L., Caspi, A., \& Moffitt, T.E. (2006). When parents have a history of conduct disorder: How is the caregiving environment affected? Journal of Abnormal Child Psychology, 115, 309-319. doi:10.1037/0021-843X.115.2.309

Lewis, M., Alessandri, S. M., \& Sullivan, M. W. (1990). Violation of expectancy, loss of control, and anger expressions in young infants. Developmental Psychology, 26, 745751. doi: 10.1037/0012-1649.26.5.745

Loranger, A.W., Sartorius, N., Andreoli, A., Berger, P., Buchheim, P., Channabasavanna, S.M., et al. (1994). The International Personality Disorder Examination (IPDE). The World Health Organization/Alcohol, Drug Abuse, and Mental Health Administration International Pilot Study of Personality Disorders. Archives of General Psychiatry, 51, 215-224. doi: 10.1001/archpsyc.1994.03950030051005

Lorber, M. F., Del Vecchio, T., \& Slep, A. M. S. (2015). The emergence and evolution of infant externalizing behavior. Development and Psychopathology, 27, 663-680. doi:10.1017/S0954579414000923

Mäki, P., Veijola, J., Rasanen, P., Joukamaa, M., Valonen, P., Jokelainen, J., \& Isohanni, M. (2003). Criminality in the offspring of antenatally depressed mothers: A 33-year follow-up of the northern Finland 1966 birth cohort. Journal of Affective Disorders, 74, 273-278. doi:10.1016/S0165-0327(02)00019-8 
Positive Parenting and Angry Aggressiveness

Maughan, B., Rowe, R., Messer, J., Goodman, R., \& Meltzer, H. (2004). Conduct Disorder and Oppositional Defiant Disorder in a national sample: Developmental epidemiology. Journal of Child Psychology and Psychiatry, 45, 609-621. doi:10.1111/j.14697610.2004.00250.x

McCutcheon, A. L. (2002). Basic concepts and procedures in single- and multiple-group latent class analysis. In J. A. Hagenaars \& McCutcheon A. L. (Eds.), Applied Latent Class Analysis. Cambridge: Cambridge University Press.

McMahon, R.J., \& Frick, P.J. (2019). Conduct and oppositional disorders. In M.J. Prinstein, E.A. Youngstrom, E.J. Mash, \& R.A. Barkley (Eds.), Treatment of disorders in childhood and adolescence (pp. 102-173). $4^{\text {th }}$ ed. London: Guildford.

Miner, J. L., \& Clarke-Stewart, K. A. (2008). Trajectories of externalizing behavior from age 2 to age 9: Relations with gender, temperament, ethnicity, parenting, and rater. Developmental Psychology, 44, 771-786. doi:10.1037/0012-1649.44.3.771

Muthén, L. K., \& Muthén, B. O. (2012). Mplus user's guide. Seventh Edition. Los Angeles, CA: Muthén \& Muthén.

Nagin, D. S., \& Tremblay, R. E. (2005). What has been learned from group-based trajectory modeling? Examples from physical aggression and other problem behaviors. The Annals of the American Academy of Political and Social Science, 602, 82-117. doi: $10.1177 / 0002716205280565$

NICHD Early Child Care Research Network. (2004). Trajectories of physical aggression from toddlerhood to middle childhood: Predictors, correlates, and outcomes. Monographs of the Society for Research in Child Development, 69, 1-143. doi: 10.1111/j.0037-976X.2004.00312.x 
Positive Parenting and Angry Aggressiveness

Nylund, K. L. (2007). Latent transition analysis: Modeling extensions and an application to peer victimization (Doctoral dissertation, University of California). Retrieved from http://www.statmodel.com/download/Nylund\%20dissertation\%20Updated1.pdf.

Pasalich, D.S., Witkiewitz, K., McMahon, R.J., Pinderhughes, E.E., and the Conduct Disorders Prevention Group. Indirect effects of the Fast Track intervention on conduct disorder symptoms and callous-unemotional traits: Distinct pathways involving discipline and warmth. Journal of Abnormal Child Psychology, 44, 587-597. doi.org/10.1007/s10802-015-0059-y

Pawlby, S., Hay, D. F., Sharp, D., Waters, C. S., \& Pariante, C. M. (2011). Antenatal depression and offspring psychopathology: The influence of childhood maltreatment. The British Journal of Psychiatry, 199, 106-112. doi: 10.1192/bjp.bp.110.087734

Pickles, A., Hill, J., Breen, G., Quinn, J., Abbott, K., Jones, H., \& Sharp, H. (2013). Evidence for interplay between genes and parenting on infant temperament in the first year of life: Monoamine oxidase A polymorphism moderates effects of maternal sensitivity on infant anger proneness. Journal of Child Psychology and Psychiatry, 54, 1308-1317. doi: 10.1111/jcpp.12081

Potegal, M., \& Davidson, R. J. (2003). Temper tantrums in young children. 1. Behavioral composition. Journal of Developmental \& Behavioral Pediatrics, 24(3), 140-147. doi: 10.1097/00004703-200306000-00002

Rice, F., Harold, G. T., Boivin, J., Hay, D. F., van den Bree, M., \& Thapar, A. (2009).

Disentangling prenatal and inherited influences in humans with an experimental design. Proceedings of the National Academy of Sciences of the United States of America, 106, 2464-2467. doi:10.1073/pnas.0808798106

Reuben, J. D., Shaw, D. S., Neiderhiser, J. M., Natsuaki, M. N., Reiss, D., \& Leve, L. D. (2016). Warm parenting and effortful control in toddlerhood: Independent and 
Positive Parenting and Angry Aggressiveness interactive predictors of school-age externalizing behavior. Journal of Abnormal Child Psychology, 44, 1083-1096. doi:10.1007/s10802-015-0096-6

Robinson, M., Mattes, E., Oddy, W. H., Pennell, C. E., van Eekelen, A., McLean, N. J., Jacoby, P., Li, J., De Klerk, N. H., Zubrick, S. R., Stanley, F. J., \& Newnham, J.P. (2011). Prenatal stress and risk of behavioral morbidity from age 2 to 14 years: The influence of the number, type, and timing of stressful life events. Development and Psychopathology, 23, 507-520. doi:10.1017/S0954579411000241

Ryoo, J. H., Wang, C., Swearer, S. M., Hull, M., \& Shi, D. (2018). Longitudinal model building using latent transition analysis: an example using school bullying data. Frontiers in psychology, 9: 675. doi: 10.3389/fpsyg.2018.00675

Socolar, R. R., \& Stein, R. E. (1995). Spanking infants and toddlers: Maternal belief and practice. Pediatrics, 95, 105-111.

Shaw, D. S., Gilliom, M., Ingoldsby, E. M., \& Nagin, D. S. (2003). Trajectories leading to school-age conduct problems. Developmental Psychology, 39, 189-200. doi:10.1037/0012-1649.39.2.189

Shaw, D. S., Lacourse, E., \& Nagin, D. S. (2005). Developmental trajectories of conduct problems and hyperactivity from ages 2 to 10. Journal of Child Psychology and Psychiatry, 46, 931-942. doi:10.1111/j.1469-7610.2004.00390.x

Smetana, J. G. (1989). Toddlers' social interactions in the context of moral and conventional transgressions in the home. Developmental Psychology, 25, 499-508. doi:10.1037/0012-1649.25.4.499

Socolar, R. R., \& Stein, R. E. (1995). Spanking infants and toddlers: Maternal belief and practice. Pediatrics, 95, 105-111.

StataCorp (Version 13) [Computer software]. College Station, TX: StataCorp LP. 
Positive Parenting and Angry Aggressiveness

Stenberg, C. R., Campos, J. J., \& Emde, R. N. (1983). The facial expression of anger in seven-month-old infants. Child Development, 54, 178-184. doi: 10.2307/1129875

Tremblay, R. E. (2003). Why socialization fails - The case of chronic physical aggression. In B.B. Lahey, T.E. Moffitt, \& A. Caspi (Eds.), Causes of conduct disorder and juvenile delinquency (pp. 182-224). New York: Guilford Press.

Tremblay, R.E. (2010). Developmental origins of disruptive behavior problems: the 'original sin hypothesis,' epigenetics, and the consequences for prevention. Journal of Child Psychology and Psychiatry, 51, 341-367. doi:10.1111/j.1469-7610.2010.0221

Tremblay, R. E., Japel, C., Perusse, D., McDuff, P., Boivin, M., Zoccolillo, M., \& Montplaisir, J. (1999). The search for the age of 'onset' of physical aggression: Rousseau and Bandura revisited. Criminal Behavior and Mental Health, 9, 8-23. doi: $10.1002 / \mathrm{cbm} .288$

Tremblay, R., Nagin, D. S., Séguin, J. R., Zoccolillo, M., Zelazo, P. D., Boivin, M., Pérusse, D., \& Japel, C. (2004). Physical aggression during early childhood: Trajectories and predictors. Pediatrics, 114, e43-e50. Retrieved from http://psycnet.apa.org/psycinfo/2005-03727-002

van Goozen, S. H. M., Fairchild, G., Snoek, H., \& Harold, G. T. (2007). The evidence for a neurobiological model of childhood antisocial behavior. Psychological Bulletin, 133, 149-182. doi: 10.1037/0033-2909.133.1.149

van Zeijl, J., Mesman, J., Stolk, M. N., Alink, L. R. A., Van IJzendoorn, M. H., BakermansKranenburg, M. J., Feramie, J., \& Koot, H. M. (2007). Differential susceptibility to discipline: The moderating effect of child temperament on the association between maternal discipline and early childhood externalizing problems. Journal of Family Psychology, 21, 626-636. doi:10.1037/0893-3200.21.4.626

von Eye, A., \& Bergmann, L.R. (2003). Research strategies in developmental 
Positive Parenting and Angry Aggressiveness psychopathology: Dimensional identity and the person-oriented approach. Development and Psychopathology, 15, 553-580. doi:10.1017/S0954579403000294

Wichstrøm, L., Berg-Nielsen, T. S., Angold, A., Egger, H. L., Solheim, E., \& Sveen, T. H. (2012). Prevalence of psychiatric disorders in preschoolers. Journal of Child Psychology and Psychiatry, 53, 695-705. doi:10.1111/j.1469-7610.2011.02514.x Development and Psychopathology, 15, 553-580. doi: 10.1017.S0954579403000294 Wing, J. K., Babor, T., Brugha, T., Burke, J., Cooper, J. E., Giel, R., Jablenski, A., Regier, D., \& Sartorius, N. (1990). SCAN: Schedules for Clinical Assessment in Neuropsychiatry. Archives of General Psychiatry, 47, 589-593. doi: 10.1001/archpsyc.1990.01810180089012 
Table 1.

Maternal characteristics before birth of the child, and parenting attitudes and behaviour when the child was 6 months.

Maternal characteristics for $N=304$

\begin{tabular}{lcc}
\hline Variable & $\mathbf{N}$ & $\mathbf{\%}$ \\
\hline Mother in her teens at birth & 40 & 13.2 \\
Mother single & 29 & 9.5 \\
Mother not married & 144 & 47.4 \\
Mother not white British/Irish & 21 & 7.2 \\
Mother working class & 143 & 47.0 \\
Mother without basic qualifications & 61 & 20.1 \\
Mother prenatal depression & 46 & 15.1 \\
\hline
\end{tabular}

Caregiver's scores in scales collected during pregnancy and during the Infancy Visit

\begin{tabular}{lccccc}
\hline Variable & Mean & SD & Min & Max & N \\
\hline $\begin{array}{l}\text { Maternal antisocial behavior (self-report) } \\
\text { Main Caregiver's endorsement of positive }\end{array}$ & 4.35 & 4.11 & 0 & 20 & 304 \\
$\begin{array}{l}\text { parenting (self-report) } \\
\text { Main Caregiver's endorsement of }\end{array}$ & 28.06 & 2.24 & 13 & 30 & 258 \\
$\begin{array}{l}\text { punishment (self-report) } \\
\begin{array}{l}\text { Main Caregiver's positive behavior observed } \\
\text { during free play }\end{array}\end{array}$ & 3.69 & 1.61 & 2 & 10 & 256 \\
$\begin{array}{l}\text { Main Caregiver's positive behavior observed } \\
\text { during joint activity task }\end{array}$ & 1.47 & 4.68 & 0 & 21 & 283 \\
$\begin{array}{l}\text { Main Caregiver's positive behavior observed } \\
\text { during infant feeding }\end{array}$ & 3.11 & 3.22 & 0 & 14 & 261 \\
$\begin{array}{l}\text { Main Caregiver's positive behavior } \\
\text { dimension }\end{array}$ & -0.00 & 0.34 & -0.78 & 0.71 & 295 \\
\hline
\end{tabular}

Note. ${ }^{1}$ Retrospective self-report measure collected during last pregnancy trimester. ${ }^{2}$ Self report measure collected around Infancy visit. ${ }^{3}$ Observed behavior during 6-month visit. ${ }^{4}$ Construct estimated with a measurement model with the positive behaviors during the Infancy visit as indicators. 
Table 2.

Descriptive associations between family and child variables and by Latent Class (LC) status and by age.

\begin{tabular}{|c|c|c|c|c|c|c|c|c|c|c|c|c|c|c|}
\hline \multirow{3}{*}{ LC Infancy } & \multirow{2}{*}{\multicolumn{2}{|c|}{ Family Adversity }} & \multicolumn{4}{|c|}{$\begin{array}{c}\text { Maternal Post-Natal } \\
\text { Depression }\end{array}$} & \multicolumn{4}{|c|}{$\begin{array}{c}\text { Maternal Antisocial } \\
\text { Behavior }\end{array}$} & \multicolumn{4}{|c|}{ Child's Gender } \\
\hline & & & \multicolumn{2}{|c|}{ Yes } & \multicolumn{2}{|c|}{ No } & \multicolumn{2}{|c|}{ High } & \multicolumn{2}{|c|}{ Low } & \multicolumn{2}{|c|}{ Male } & \multicolumn{2}{|c|}{ Female } \\
\hline & Mean & $\mathrm{SD}$ & $\mathrm{n}$ & $\%$ & $\mathrm{n}$ & $\%$ & $\mathrm{n}$ & $\%$ & $\mathrm{n}$ & $\%$ & $\mathrm{n}$ & $\%$ & $\mathrm{n}$ & $\%$ \\
\hline $\mathrm{HH}$ & 0.72 & 1.26 & 6 & 13 & 10 & 4 & 12 & 9 & 4 & 2 & 12 & 7 & 4 & 3 \\
\hline HM & 0.24 & 1.07 & 28 & 61 & 103 & 40 & 64 & 47 & 67 & 40 & 81 & 47 & 50 & 38 \\
\hline LL & -0.38 & 0.72 & 12 & 26 & 145 & 56 & 59 & 44 & 98 & 58 & 80 & 46 & 77 & 59 \\
\hline Summary stats & $F(2,301)=22.27$ & $p<.001$ & \multicolumn{2}{|c|}{$\chi^{2}(2)=17.06$} & \multicolumn{2}{|c|}{$p<.001$} & \multicolumn{2}{|c|}{$\chi^{2}(2)=10.08$} & \multicolumn{2}{|c|}{$p=.006$} & \multicolumn{2}{|c|}{$\chi^{2}(2)=5.70$} & \multicolumn{2}{|c|}{$p=.058$} \\
\hline \multirow[t]{2}{*}{ LC Toddlerhood } & & & & & & & & & & & & & & \\
\hline & Mean & SD & $\mathrm{n}$ & $\%$ & $\mathrm{n}$ & $\%$ & $\mathrm{n}$ & $\%$ & $\mathrm{n}$ & $\%$ & $\mathrm{n}$ & $\%$ & $\mathrm{n}$ & $\%$ \\
\hline $\mathrm{HH}$ & -0.04 & 1.07 & 11 & 24 & 38 & 15 & 25 & 48 & 24 & 14 & 29 & 17 & 20 & 15 \\
\hline HM & 0.06 & 1.00 & 31 & 67 & 153 & 59 & 90 & 67 & 94 & 56 & 105 & 61 & 79 & 60 \\
\hline LL & -0.36 & 0.78 & 4 & 9 & 67 & 26 & 20 & 15 & 51 & 30 & 39 & 22 & 32 & 25 \\
\hline Summary stats & $F(2,301)=4.94$ & $p=.008$ & $\chi^{2}(2)=$ & & $p=$. & & $\chi^{2}(2)=$ & & $p=$. & & $\chi^{2}(2)=$ & .22 & $p=$. & \\
\hline
\end{tabular}

\begin{tabular}{|c|c|c|c|c|c|c|c|c|c|c|c|c|c|c|}
\hline \multirow{2}{*}{$\begin{array}{l}\text { LC Early } \\
\text { Childhood }\end{array}$} & \multirow[b]{2}{*}{ Mean } & \multirow[b]{2}{*}{ SD } & \multirow[b]{2}{*}{$\mathrm{n}$} & \multirow[b]{2}{*}{$\%$} & \multirow[b]{2}{*}{$\mathrm{n}$} & \multirow[b]{2}{*}{$\%$} & \multirow[b]{2}{*}{$\mathrm{n}$} & \multirow[b]{2}{*}{$\%$} & \multirow[b]{2}{*}{$\mathrm{n}$} & \multirow[b]{2}{*}{$\%$} & \multirow[b]{2}{*}{$\mathrm{n}$} & \multirow[b]{2}{*}{$\%$} & \multirow[b]{2}{*}{$\mathrm{n}$} & \multirow[b]{2}{*}{$\%$} \\
\hline & & & & & & & & & & & & & & \\
\hline $\mathrm{HH}$ & 0.09 & 1.10 & 12 & 26 & 36 & 14 & 28 & 21 & 20 & 12 & 27 & 16 & 21 & 16 \\
\hline HM & -0.03 & 0.99 & 30 & 65 & 183 & 71 & 95 & 70 & 118 & 70 & 129 & 74 & 84 & 64 \\
\hline LL & -0.32 & 0.71 & 4 & 9 & 39 & 15 & 12 & 9 & 31 & 18 & 17 & 10 & 26 & 20 \\
\hline Summary stats & $F(2,301)=2.18$ & $p=.115$ & $\chi^{2}(2)=$ & & $p=$. & & $\chi^{2}(2)=$ & & $p=$. & 14 & $\chi^{2}(2)=$ & 6.46 & $p=$ & \\
\hline
\end{tabular}

Note: HH = High Anger -High Aggression; HM = High Anger - Moderate Aggression; LL = Low Anger - Low Aggression 
Table 3.

Probabilities of transitioning from one angry-aggressive class to another across age.

\begin{tabular}{|c|c|c|c|c|}
\hline Infancy & \multicolumn{3}{|c|}{ Toddlerhood } & Total \\
\hline $\mathrm{HH}$ & 0.53 & 0.47 & 0 & 1 \\
\hline HM & 0.21 & 0.69 & 0.10 & 1 \\
\hline LL & 0.10 & 0.48 & 0.42 & 1 \\
\hline Toddlerhood & $\mathrm{HH}$ & $\begin{array}{l}\text { Chilc } \\
\text { HM }\end{array}$ & LL & Total \\
\hline $\mathrm{HH}$ & 0.63 & 0.30 & 0.07 & 1 \\
\hline HM & 0.11 & 0.77 & 0.12 & 1 \\
\hline LL & 0.03 & 0.59 & 0.38 & 1 \\
\hline
\end{tabular}

Note: $H H=$ High Anger -High Aggression; HM = High Anger - Moderate Aggression; LL = Low Anger - Low Aggression;

Stability probabilities (i.e. probability of remaining in the same class across two adjacent measurement points) are shaded. 
Table 4.

Odds ratios (OR) and 95\% CI (Confidence Intervals) of being in the High Anger-High Aggression (HH) and High Anger-Moderate Aggression (HM) angry-aggressive categories compared to the Low Anger-Low Aggression (LL) category by age, N=304. ORs in Toddlerhood and Early Childhood are adjusted controlling for angry aggressiveness status in the previous measurement occasion. In this way, the ORs represent changes in the odds of transitioning into an angry aggressiveness category rather than the reference one (LL).

\begin{tabular}{|c|c|c|c|c|c|c|c|c|}
\hline Infancy & & $\begin{array}{c}\text { HH } \\
O R\end{array}$ & $95 \%$ & $C I$ & $\begin{array}{c}\text { HM } \\
\text { OR }\end{array}$ & $95 \%$ & $C I$ & $\begin{array}{l}\mathbf{L L} \\
\text { (Reference category) }\end{array}$ \\
\hline $\begin{array}{l}\text { Child's } \\
\text { gender }\end{array}$ & $\begin{array}{l}\text { Female } \\
\text { Male }\end{array}$ & $\begin{array}{c}\text { reference } \\
2.734\end{array}$ & 0.573 & 13.058 & $\begin{array}{c}\text { reference } \\
1.758\end{array}$ & 0.952 & 3.244 & --- \\
\hline $\begin{array}{l}\text { Maternal } \\
\text { antenatal depression }\end{array}$ & $\begin{array}{l}\text { No } \\
\text { Yes }\end{array}$ & $\begin{array}{c}\text { reference } \\
3.283\end{array}$ & 0.717 & 15.036 & $\begin{array}{l}\text { reference } \\
2.085\end{array}$ & 0.704 & 6.169 & --- \\
\hline $\begin{array}{l}\text { Maternal antisocial } \\
\text { behavior }\end{array}$ & $\begin{array}{l}<=\operatorname{Mdn} \\
>\operatorname{Mdn}\end{array}$ & $\begin{array}{c}\text { reference } \\
1.886\end{array}$ & 0.163 & 21.771 & $\begin{array}{c}\text { reference } \\
0.739\end{array}$ & 0.367 & 1.485 & --- \\
\hline Sociodemographic adversity & & $3.118^{+}$ & 0.995 & 9.764 & $2.095 * *$ & 1.354 & 3.242 & --- \\
\hline Toddlerhood & & $\begin{array}{r}\text { HH } \\
O R \\
\end{array}$ & $95 \%$ & $C I$ & $\begin{array}{c}\text { HM } \\
O R \\
\end{array}$ & $95 \%$ & $C I$ & $\begin{array}{l}\mathbf{L L} \\
\text { (Reference category) }\end{array}$ \\
\hline $\begin{array}{l}\text { Child's } \\
\text { gender }\end{array}$ & $\begin{array}{l}\text { Female } \\
\text { Male }\end{array}$ & $\begin{array}{c}\text { reference } \\
0.642\end{array}$ & 0.219 & 1.884 & $\begin{array}{c}\text { reference } \\
0.787\end{array}$ & 0.355 & 1.744 & --- \\
\hline $\begin{array}{l}\text { Maternal } \\
\text { antenatal depression }\end{array}$ & $\begin{array}{l}\text { No } \\
\text { Yes }\end{array}$ & $\begin{array}{l}\text { reference } \\
2.765\end{array}$ & 0.471 & 16.244 & $\begin{array}{c}\text { reference } \\
1.862\end{array}$ & 0.400 & 8.667 & --- \\
\hline $\begin{array}{l}\text { Maternal antisocial } \\
\text { behavior }\end{array}$ & $\begin{array}{l}<=\operatorname{Mdn} \\
>\operatorname{Mdn}\end{array}$ & $\begin{array}{c}\text { reference } \\
3.333\end{array}$ & 0.937 & 11.854 & $\begin{array}{l}\text { reference } \\
\mathbf{2 . 5 5 6 *}\end{array}$ & 1.034 & 6.314 & --- \\
\hline Sociodemographic adversity & & 0.645 & 0.309 & 1.345 & 0.822 & 0.454 & 1.488 & --- \\
\hline Early Childhood & & $\begin{array}{r}\text { HH } \\
O R\end{array}$ & $95 \%$ & $C I$ & $\begin{array}{l}\text { HM } \\
O R\end{array}$ & $95 \%$ & $C I$ & $\begin{array}{l}\mathbf{L L} \\
\text { (Reference category) }\end{array}$ \\
\hline $\begin{array}{l}\text { Child's } \\
\text { gender }\end{array}$ & $\begin{array}{l}\text { Female } \\
\text { Male }\end{array}$ & $\begin{array}{l}\text { reference } \\
2.270\end{array}$ & 0.434 & 11.867 & $\begin{array}{l}\text { reference } \\
\text { 3.571* }\end{array}$ & 1.003 & 12.716 & --- \\
\hline $\begin{array}{l}\text { Maternal } \\
\text { prenatal depression }\end{array}$ & $\begin{array}{l}\text { No } \\
\text { Yes }\end{array}$ & $\begin{array}{c}\text { reference } \\
1.240\end{array}$ & 0.194 & 7.930 & $\begin{array}{c}\text { reference } \\
0.727\end{array}$ & 0.178 & 2.966 & --- \\
\hline $\begin{array}{l}\text { Maternal antisocial } \\
\text { behavior }\end{array}$ & $\begin{array}{l}<=\operatorname{Mdn} \\
>\operatorname{Mdn}\end{array}$ & $\begin{array}{l}\text { reference } \\
2.269\end{array}$ & 0.445 & 11.573 & $\begin{array}{c}\text { reference } \\
1.252\end{array}$ & 0.381 & 4.109 & --- \\
\hline Sociodemographic adversity & & 1.106 & 0.525 & 2.333 & 0.879 & 0.502 & 1.537 & --- \\
\hline
\end{tabular}

Note: ${ }^{+} p<.06 ; \quad{ }^{*} p<.05 ; * * p<.01$ 
Table 5 .

Means and SD of parenting variables measured in infancy by Latent Class (LC) status and by age. Parenting variables were regressed on the nominal latent class affiliation with summary statistics reported.

\begin{tabular}{|c|c|c|c|c|c|c|}
\hline & \multicolumn{2}{|l|}{ Positive Affect } & \multicolumn{2}{|l|}{ Warm Parenting } & \multicolumn{2}{|c|}{ Endorsement of Punishment } \\
\hline LC Infancy & Mean & $S D$ & Mean & $S D$ & Mean & $S D$ \\
\hline $\mathrm{HH}$ & -0.11 & 1.15 & 0.02 & 1.39 & -0.17 & 1.00 \\
\hline HM & -0.06 & 1.05 & -0.07 & 1.00 & 0.11 & 1.02 \\
\hline LL & 0.09 & 0.93 & 0.05 & 0.97 & -0.07 & 0.98 \\
\hline \multirow[t]{2}{*}{ Summary regression } & $F(2,281)=0.89$ & $p=.41$ & $F(2,255)=0.40$ & $p=.67$ & $F(2,253)=1.14$ & $p=.32$ \\
\hline & \multicolumn{2}{|l|}{ Positive Affect } & \multicolumn{2}{|l|}{ Warm Parenting } & \multicolumn{2}{|c|}{ Endorsement of Punishment } \\
\hline LC Toddlerhood & Mean & $S D$ & Mean & $S D$ & Mean & $S D$ \\
\hline $\mathrm{HH}$ & -0.17 & 1.03 & -0.23 & 1.11 & 0.03 & 0.91 \\
\hline HM & -0.03 & 1.00 & -0.02 & 0.98 & 0.01 & 1.04 \\
\hline LL & 0.25 & 0.91 & 0.20 & 0.95 & -0.05 & 0.96 \\
\hline \multirow[t]{2}{*}{ Summary regression } & $F(2,281)=2.93^{+}$ & $p=.05$ & $F(2,255)=2.36^{+}$ & $p=.09$ & $F(2,253)=0.11$ & $p=.90$ \\
\hline & \multicolumn{2}{|l|}{ Positive Affect } & \multicolumn{2}{|l|}{ Warm Parenting } & \multicolumn{2}{|c|}{ Endorsement of Punishment } \\
\hline LC Early Childhood & Mean & $S D$ & Mean & $S D$ & Mean & $S D$ \\
\hline $\mathrm{HH}$ & -0.15 & 1.02 & -0.24 & 1.06 & -0.08 & 0.98 \\
\hline $\mathrm{HM}$ & -0.07 & 0.95 & 0.02 & 0.99 & 0.06 & 1.00 \\
\hline LL & 0.63 & 0.91 & 0.11 & 0.96 & -0.19 & 1.00 \\
\hline Summary regression & $F(2,281)=10.26^{*}$ & $p<.001$ & $F(2,255)=1.39$ & $p=.25$ & $F(2,253)=1.13$ & $p=.32$ \\
\hline
\end{tabular}

Note: $H H=$ High Anger-High Aggression; HM = High Anger - Moderate Aggression; LL = Low Anger - Low Aggression 
Table 6.

Adjusted Odds ratios (OR) and Standard Errors (SE) of being in the High Anger-High Aggression (HH) and High Anger-Moderate Aggression (HM) angry-aggressive categories compared to the Low Anger-Low Aggression (LL) category, by parenting variables and by age, $N=304$. ORs in Toddlerhood and Early Childhood are adjusted controlling for angry aggressiveness status in the previous measurement occasion. In this way, the ORs represent changes in the odds of transitioning into an angry aggressiveness category rather than the reference one (LL).

\begin{tabular}{|c|c|c|c|c|c|c|c|}
\hline & HH & & & HM & & & $\begin{array}{l}\text { LL (Reference } \\
\text { category) }\end{array}$ \\
\hline Infancy & OR & $S E$ & $p$ & OR & $S E$ & $p$ & \\
\hline Positive Affect & 1.19 & 0.48 & .71 & 0.79 & 0.17 & .15 & --- \\
\hline Warm Parenting Beliefs & 0.86 & 1.05 & .88 & 0.95 & 0.16 & .77 & --- \\
\hline & HH & & & HM & & & $\begin{array}{l}\text { LL (Reference } \\
\text { category) }\end{array}$ \\
\hline Toddlerhood & $O R$ & $S E$ & $p$ & $O R$ & $S E$ & $p$ & \\
\hline Positive Affect & 0.81 & 0.28 & .47 & 0.82 & 0.25 & .44 & $\begin{array}{c}-- \\
-\end{array}$ \\
\hline Warm Parenting Beliefs & $0.48 *$ & $\mathbf{0 . 3 3}$ & .03 & $0.56 *$ & 0.27 & .03 & --- \\
\hline & HH & & & HM & & & $\begin{array}{l}\text { LL (Reference } \\
\text { category) }\end{array}$ \\
\hline Early Childhood & $O R$ & $S E$ & $p$ & $O R$ & $S E$ & $p$ & \\
\hline Positive Affect & $0.32 * *$ & 0.29 & .006 & $0.34 * * *$ & 0.29 & $<.001$ & --- \\
\hline Warm Parenting Beliefs & 1.19 & 0.33 & .60 & 1.12 & 0.24 & .64 & --- \\
\hline
\end{tabular}

Note: $* p<.05 ; \quad * * p<.01 ; \quad * * * p<.001$. Parameters are estimated across 50 completed datasets created using multiple imputation. When estimating parameters based on multiple imputations, Mplus does not estimate 95\% Confidence Intervals. Here we report the SE of the ORs. The models controlled for associations between latent classes and other covariates (child gender; family adversity; prenatal depression; maternal history of conduct problems). 
Table 7.

Number and percentages of participants in angry aggressive classes at each time point who met criteria for CD/ODD at 7 years.

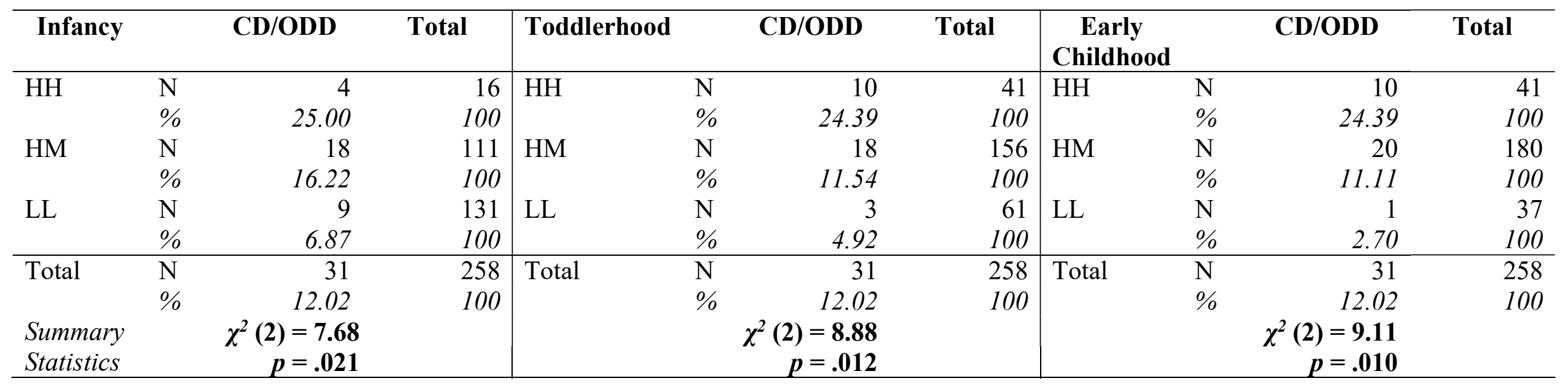

Note: $\mathrm{HH}=$ High Anger-High Aggression; HM = High Anger - Moderate Aggression; LL = Low Anger - Low Aggression. 

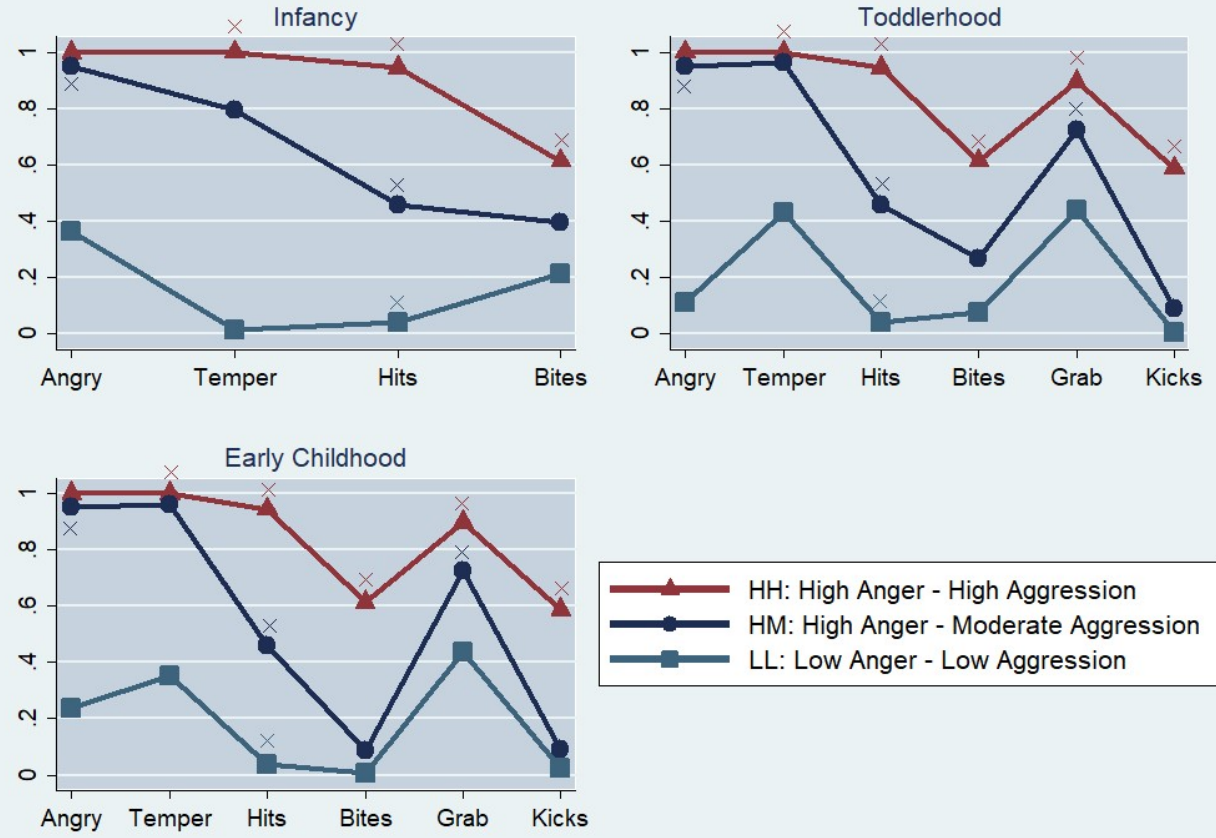

$\mathrm{HH}:$ High Anger - High Aggression HM: High Anger - Moderate Aggression LL: Low Anger - Low Aggression

Figure 1. Conditional cumulative probability of behaviors being reported to appear with moderate frequency or more by latent class and by age. The stars indicate indicator behavior whose conditional frequency was invariant across age points where the behavior was considered. 


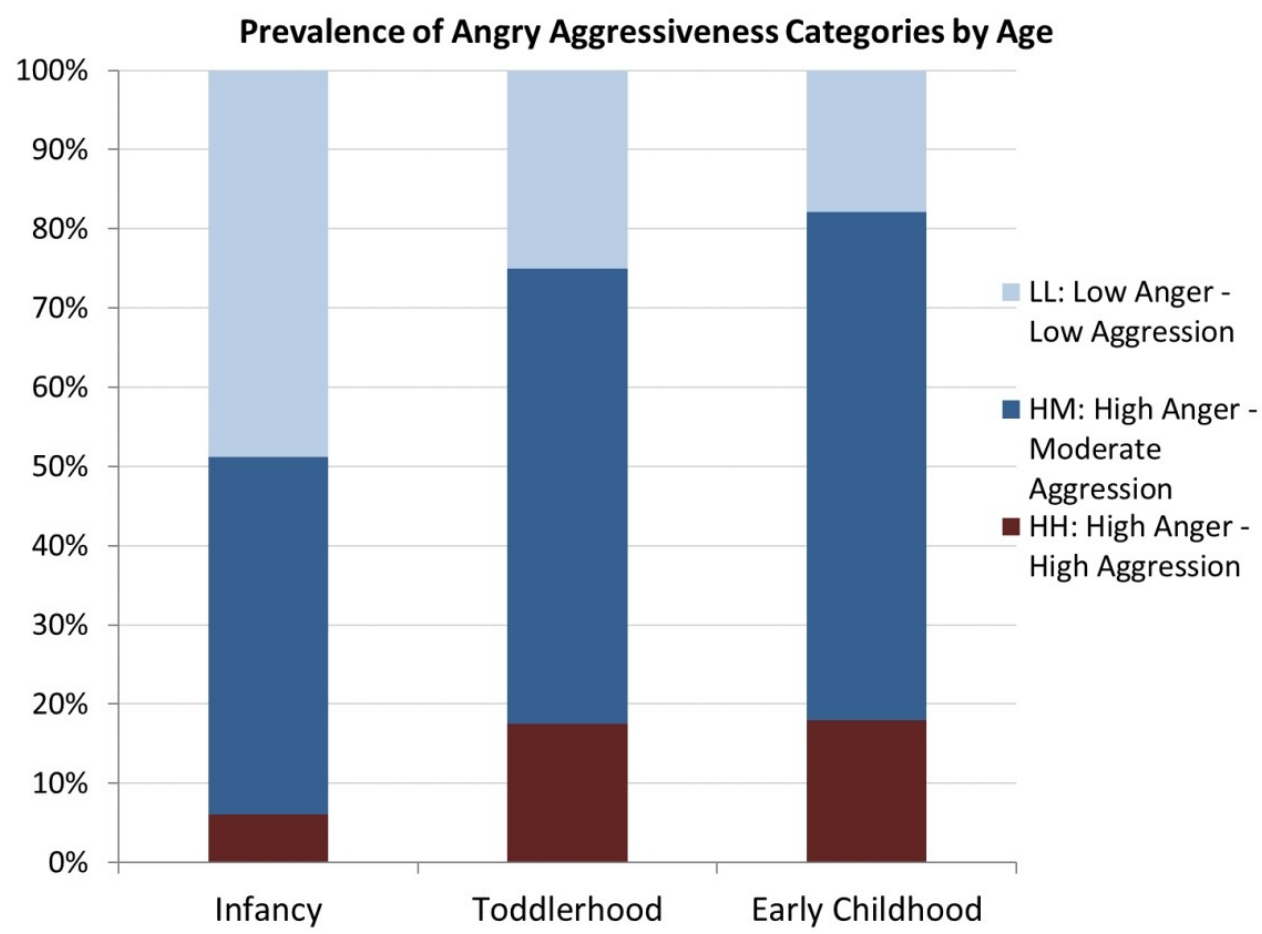

Figure 2. Prevalence of angry-aggressive behavior categories by age. 

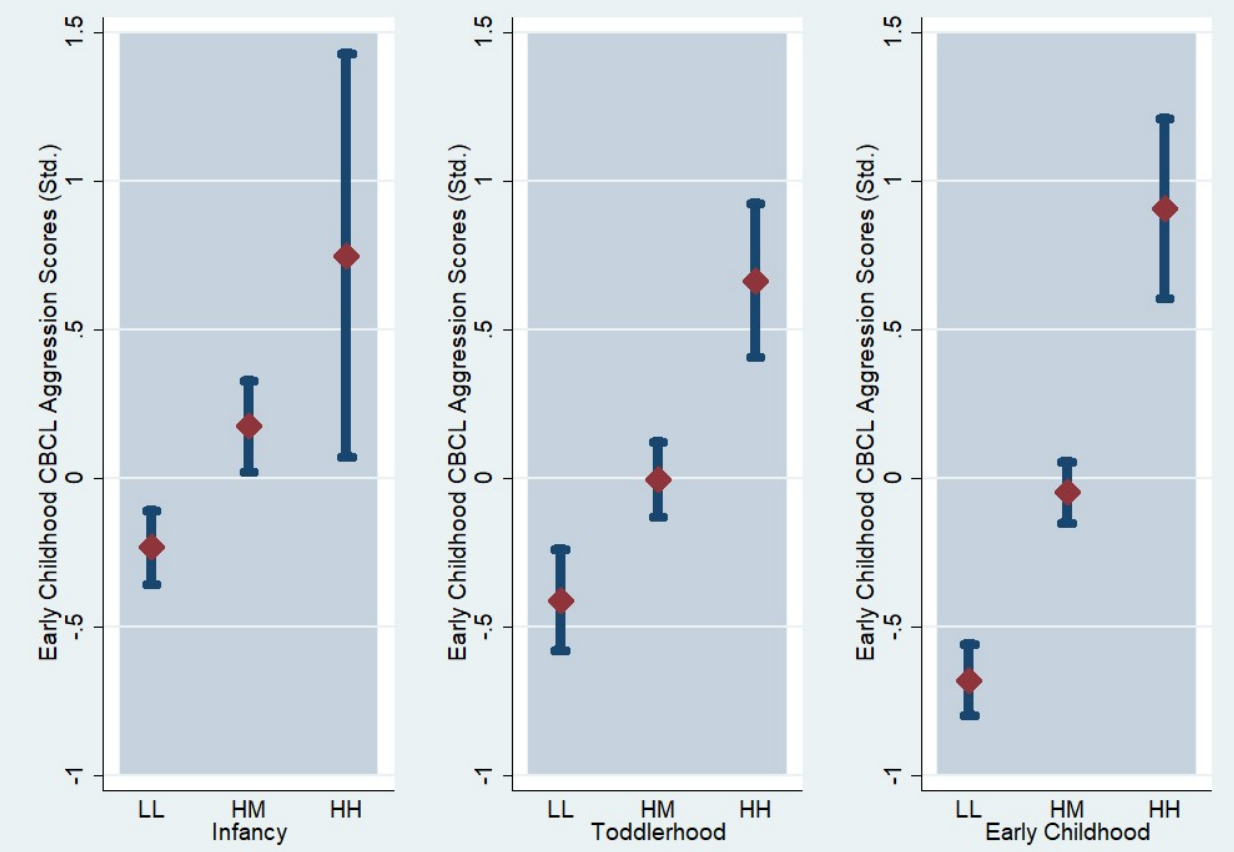

HH: High Anger - High Aggression; HM: High Anger - Moderate Aggressıon ; LL: Low Anger - Low Aggression

Figure 3. Means and 95\% confidence intervals of standardised CBCL Aggression scores by latent angryaggressive class by age. 


\section{Page 65 of 65}
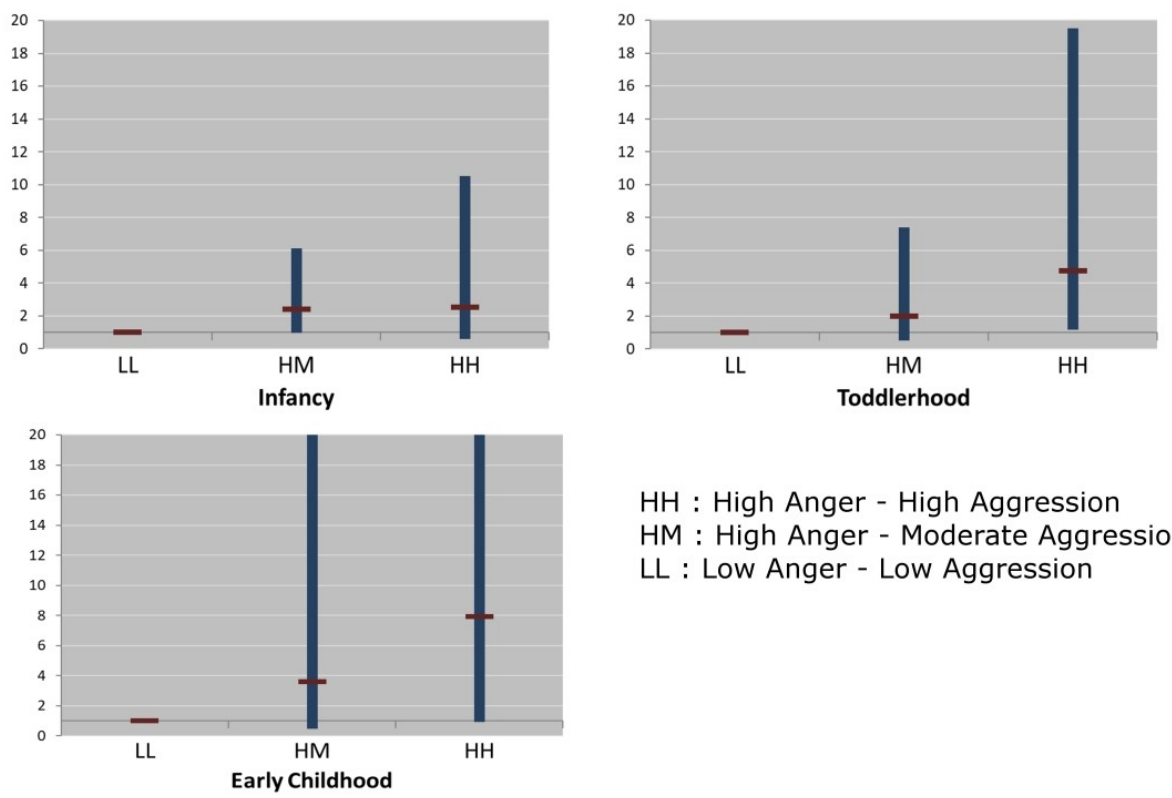

$\mathrm{HH}:$ High Anger - High Aggression HM : High Anger - Moderate Aggression LL : Low Anger - Low Aggression

Figure 4. Odds ratios (and 95\% CIs) of meeting criteria for CD/ODD at 7 years by angry aggressivelatent class affiliation at 6,21 , and 36 months ( $L L$ is the reference class). $F(5,13452.0)=4.11, p=.0012$ for 6 months, $F(5,10352.5)=4.11, p=.0010$ for 21 months, and $F(5,14523.8)=4.09, p=.0010$ for 36 months. 
Figure 1A.

\section{Supplementary Materials}

Frequencies of responses by item and by measurement occasion. Responses categories were derived by averaging scores across informants. Higher scores indicate more frequent display of behaviour
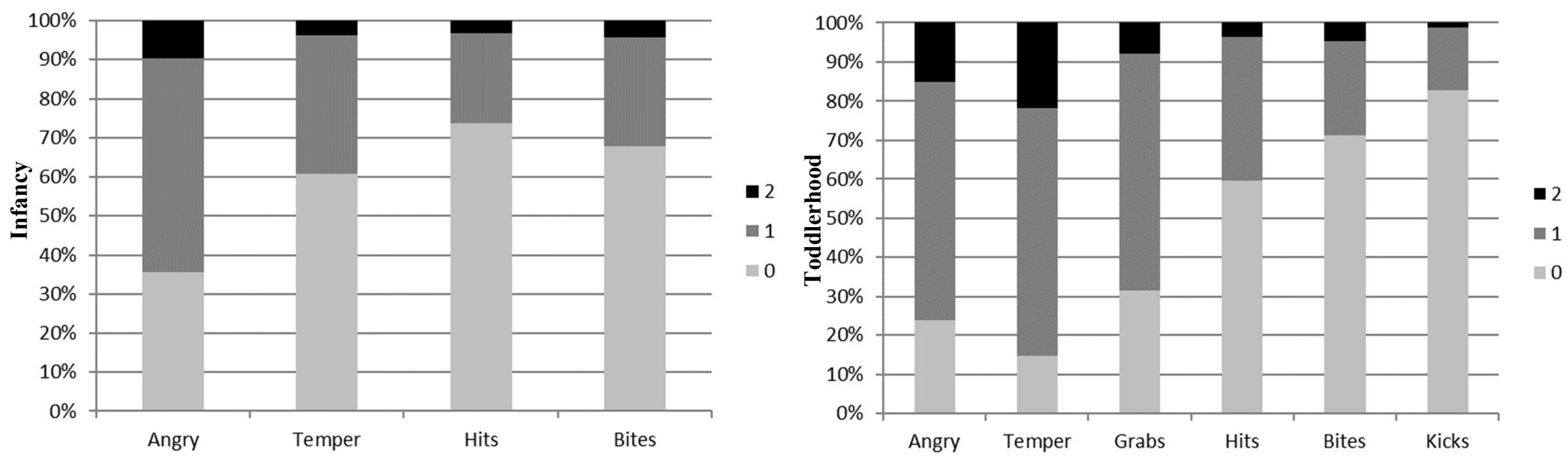

Table 1A.

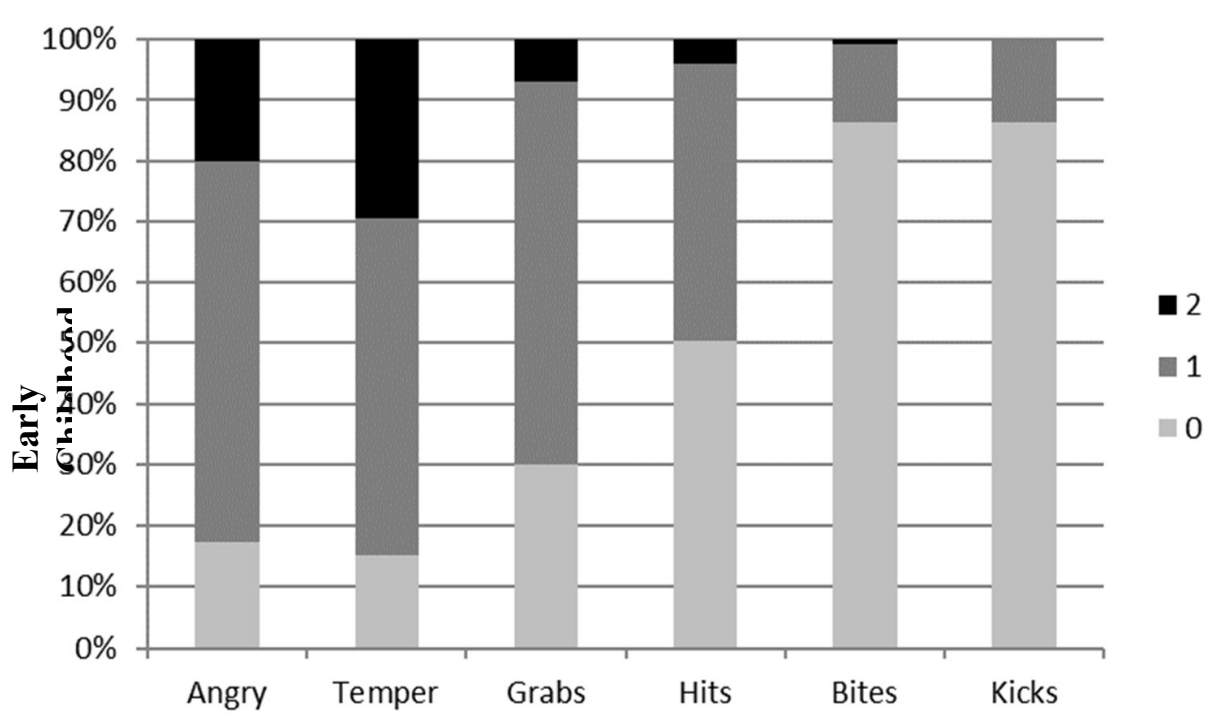

Log-Likelihood (LL) and LL correction factor, Information Criteria, and Entropy of latent class models of angry-aggressiveness by age, displayed in order of increasing latent number of latent classes. 


\begin{tabular}{|c|c|c|c|c|c|c|}
\hline Age and number and type of classes & LL & $\begin{array}{l}\text { LL } \\
\text { Correction } \\
\text { Factor }\end{array}$ & Parameters & $\mathrm{BIC}$ & $\mathrm{aBIC}$ & Entropy \\
\hline Infancy: 2 classes & -3083.12 & 1.01 & 40 & 6394.93 & 6268.07 & 0.85 \\
\hline Infancy: 3 classes & -3053.05 & 1.06 & 49 & 6386.23 & 6230.83 & 0.84 \\
\hline Infancy: 3-ordered classes & -3060.03 & 1.00 & 41 & 6354.46 & 6224.43 & 0.79 \\
\hline Infancy: 4 classes & -3046.37 & 1.00 & 58 & 6424.32 & 6240.37 & 0.86 \\
\hline Infancy: 4-ordered classes & -3058.6 & 1.06 & 42 & 6357.32 & 6224.12 & 0.83 \\
\hline Toddlerhood: 2 classes & -3061.72 & 1.04 & 44 & 6374.99 & 6235.44 & 0.73 \\
\hline Toddlerhood: 3 classes & -3008.82 & 1.02 & 57 & 6343.52 & 6162.74 & 0.72 \\
\hline Toddlerhood: 3 -ordered classes & -3015.77 & 1.02 & 45 & 6288.8 & 6146.08 & 0.72 \\
\hline Toddlerhood: 4 classes & -2993.86 & 1.02 & 70 & 6387.9 & 6165.9 & 0.77 \\
\hline Toddlerhood: 4-ordered classes & -3010.42 & 1.10 & 46 & 6283.82 & 6137.93 & 0.76 \\
\hline Early Childhood: 2 classes & -3094.26 & 1.02 & 43 & 6434.35 & 6297.97 & 0.66 \\
\hline Early Childhood: 3 classes & -3055.74 & 1.03 & 55 & 6425.92 & 6251.49 & 0.66 \\
\hline Early Childhood: 3 -ordered classes & -3066.4 & 1.05 & 44 & 6384.35 & 6244.80 & 0.66 \\
\hline Early Childhood: 4 classes & -3036.92 & 1.03 & 67 & 6456.89 & 6244.39 & 0.72 \\
\hline Early Childhood: 4-ordered classes & -3065.13 & 1.02 & 45 & 6387.53 & 6244.81 & 0.61 \\
\hline
\end{tabular}


Table 2A.

Adjusted Odds Ratios (OR) and Standard Errors (SE) of being in the High or Moderate angry-aggressive class compared to the Low angryaggressive class, by parental Endorsement of Physical Punishment and by age, $N=304$.

\begin{tabular}{|c|c|c|c|c|c|c|c|}
\hline & High & & & Moderate & & & Low (Reference category) \\
\hline Infancy & OR & $S E$ & $p$ & OR & $S E$ & $p$ & \\
\hline \multirow[t]{2}{*}{ Endorsement of Punishment } & 0.91 & 0.35 & .79 & 1.10 & 0.17 & .56 & --- \\
\hline & High & & & Moderate & & & Low (Reference category) \\
\hline Toddlerhood & OR & $S E$ & $p$ & OR & $S E$ & $p$ & \\
\hline \multirow[t]{2}{*}{ Endorsement of Punishment } & 1.18 & 0.31 & .60 & 1.04 & 0.24 & .87 & --- \\
\hline & High & & & Moderate & & & Low (Reference category) \\
\hline Early Childhood & OR & $S E$ & $p$ & $O R$ & $S E$ & $p$ & \\
\hline Endorsement of Punishment & 0.80 & 0.43 & .61 & 1.64 & 0.30 & .10 & $\begin{array}{ll}--- \\
\end{array}$ \\
\hline
\end{tabular}

Note: Parameters are estimated across 50 completed datasets created using multiple imputation. When estimating parameters based on multiple imputations, Mplus does not estimate 95\% Confidence Intervals. Here we report the SE of the ORs. The models controlled for associations between latent classes and other covariates (child sex; family adversity; maternal antenatal depression; maternal history of conduct problems). In these latent class models, the latent class affiliation at 21 and 33 months was estimated controlling for latent class affiliation at the previous age. 